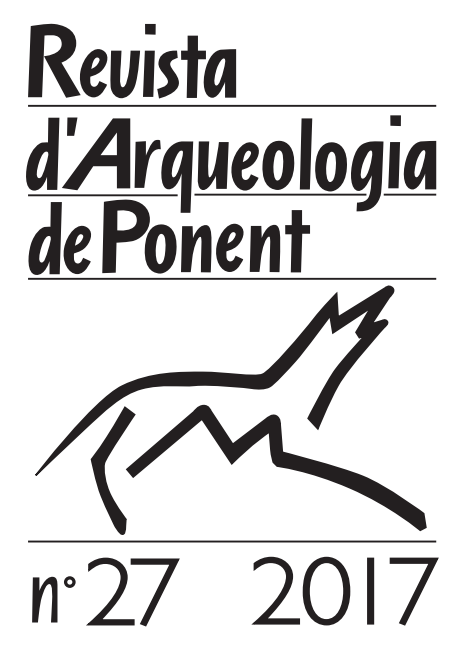

\title{
La investigació arqueològica en el sistema públic de ciència: grups de recerca, universitats $i$ instituts
}

\section{The archaeological research in the science public system: research groups, universities and institutes}

\author{
Edició: \\ Núria Rafel \\ Emili Junyent \\ Natàlia Alonso
}

Des dels anys setanta del segle passat, la disciplina arqueològica viu en estat de crisi, com a resposta a la necessitat contínua de qüestionar-se i transformar-se, exigida pels canvis econòmics, polítics i socials i les noves demandes plantejades per la societat. En cada moment, però, la crisi s'ha manifestat amb característiques pròpies segons els desencadenants puntuals o estructurals, ha tingut les corresponents conseqüències epistemològiques i factuals i ha afectat de manera distinta els diferents àmbits i protagonistes del seu exercici.
Molt probablement, la pràctica totalitat del collectiu també coincidirà a considerar la darrera dècada marcada per dos fets: el primer, l'eclosió de la gestió integrada (ICOMOS, Lausana 1990), ${ }^{1}$ el boom de l'activitat professionalitzada al marge de l'acadèmia durant el període de bonança econòmica, 2001-2008, i la posterior i brutal caiguda després de la crisi financera i, en particular, de l'anomenada "bombolla

1. <https://www.icomos.org/images/DOCUMENTS/Charters/ arch_sp.pdf $>$. 
del totxo" (desaparició d'empreses i llocs de treball, freelance llançats a l'atur...); el segon, la implementació del Pla de Bolonya i l'Espai Europeu d’Educació Superior (2010) i la greu incidència de les retallades en el finançament de la recerca i en els pressupostos universitaris, en especial, sobre unes plantilles en caiguda lliure (piràmide d'edat, extinció, manca de renovació i precarització de les places) i uns centres que es trobaven en un moment de màxima exigència de renovació de continguts i de definició de nous itineraris formatius (d'investigadors/ores orientats a la recerca bàsica transdisciplinària, a l'arqueologia professional "de gestió" o "de mercat" i al món de la socialització del patrimoni).

Endinsar-se en aquestes qüestions, les causes, conseqüències i possibles solucions, exigeix obrir moltes altres referides, posem per cas, a la caracterització i ubicació de l'arqueologia entre les diferents disciplines socials i naturals i el seu encaix en les polítiques científiques i el sistema de $\mathrm{R}+\mathrm{D}+\mathrm{I}$; o referides a la concepció i funcionament de la institució universitària, com el tipus de formació a oferir; el manteniment d'un cos de professors/investigadors o la conveniència de separar docència i recerca; el llast de l'endogàmia i els interessos corporatius en una estructura en què encara sobreviuen les àrees de coneixement; la inadequació del marc departamental a les necessitats dels grups de recerca; el dèficit en la multi i la transdisciplinarietat dels equips; els sistemes i efectes de l'avaluació de grups, projectes i publicacions; els criteris per reconèixer i mesurar l'excel-lència; el finançament i la captació de recursos; els reptes i riscos de la transferència del coneixement $i$ la recerca de finançament... La diversitat i complexitat de les qüestions plantejades, totes elles entrelligades, obliga a rebutjar reduccions simplistes de la crisi a un problema més o menys conjuntural de manca de recursos i d'insuficiència de plantilles i condemna com a suïcides actituds de mera supervivència a l'espera que tornin "els bons temps"; per altra banda, la solució de bona part dels temes apuntats exigeix la implicació del col-lectiu disciplinari en la mesura que és part del problema i ho ha de ser de la solució.

Estem davant d'una crisi, doncs — podríem dir-, de model, estructural o sistèmica, que pot ser analitzada des de diferents perspectives i a partir de múltiples manifestacions. Per aquesta raó, hem volgut centrar el debat en la recerca arqueològica bàsica o fonamental, en la producció de coneixement en els centres i organismes públics i, més concretament, en la relació entre instituts de recerca i universitats. Diverses raons ens han portat a posar-hi el focus. Primera, el relatiu èxit del sistema català de $\mathrm{R}+\mathrm{D}+\mathrm{I}$, a partir del nomenament d'Andreu Mas Collell com a comissionat d'Universitats i Investigació, creació d'instituts o centres CERCA i selecció i contractació de talent científic ICREA (2001), que ha estat pres com a referència per altres administracions autonòmiques espanyoles; segona, els instituts o centres CERCA constitueixen la principal aposta de la Generalitat de Catalunya per potenciar una recerca científica d'excel-lència $i$, en conseqüència, reben un finançament estable privilegiat; tercera, es creen com a resposta als centres universitaris i els seus problemes de governança, estructures de deci- sió burocratitzades i manca de flexibilitat i apliquen un model de gestió privada gerencial i disposen de plantilles de personal investigador i recursos per ser competitius; i, quarta, cal valorar si anem cap a un model de progressiva marginació de la recerca d'excel-lència de les universitats, en un context de competència desigual, o si ho fem cap a un model mixt que en igualtat de condicions no hauria de fer por ni tenir efectes perniciosos.

La situació és lluny de ser tranquil.litzadora. Tornem a les dues qüestions més sagnants que en aquests moments afecten la recerca en general i les universitats en particular, la minva any rere any dels fons dedicats a la investigació i la decadència constant dels quadres docents de les universitats.

Pel que fa a la primera, la situació a l'Estat espanyol és extremament preocupant. Sobretot perquè no es tracta d'una simple pèrdua de diners per a la investigació sinó d'una qüestió que ha esdevingut tan punyent que està donant com a resultat la destrucció de tot el sistema d'I+D+I espanyol:

El fuerte retroceso experimentado en los importes totales desde el año 2009, no puede medirse solamente en función de la evolución de cada año porque la persistencia de los recortes en el tiempo genera un efecto acumulado al que se ha hecho referencia en anteriores informes. Como se decía en el informe de los Presupuestos de 2016, la realización de sencillos ejercicios de simulación llevaba a la conclusión rotunda de que la acumulación de los recortes presupuestarios ha puesto en serias dificultades un sistema de innovación que lentamente se había construido en las décadas finales del siglo xx. Hoy el déficit acumulado supera los $20.000 \mathrm{M} €$ en euros constantes. La relevancia de la cifra se comprende fácilmente al compararla con los poco más de 6.500 M€ del presupuesto para $2017 .^{2}$

Pel que fa a la segona qüestió, la congelació de les plantilles de funcionaris docents de les universitats, la baixa contractació - en condicions de tan extrema precarietat que ens sentim temptats de qualificar-les d'infrahumanes- del que s'anomena eufemísticament joves (que la major part de vegades són en la quarantena o ben a prop) que no poden ni per dedicació ni per normativa legal demanar ni participar en projectes, la pressió per augmentar la dedicació docent i la falta de reconeixement de la recerca portada a terme pels docents universitaris duu les universitats a una situació de continuat descens de la competitivitat amb efectes adversos cada cop més manifestos en l'obtenció de projectes i recursos.

En perfecta, i negativa, consonància amb tot això, en els pressupostos de l'Estat la formació de personal docent $\mathrm{i}$ investigador ha patit també en els últims anys una minva quantitativa enorme. El finançament dedicat a formació de personal investigador i de professorat universitari ha anat disminuint de tal manera entre 2010 i 2017 que la pèrdua acumulada és quasi d'un $50 \% .^{3}$

2. José de Nó, José Molero (2017). Análisis de los recursos destinados a $I+D+I$ (Política de Gasto 46) contenidos en los Presupuestos Generales del Estado Aprobados para el año 2017. Confederación de Sociedades Científicas de España.

3. Ibídem nota 1: 25 . 
La nova política universitària ${ }^{4}$ està portant a una disminució cada cop més crítica de la capacitat investigadora de les institucions universitàries i és ací on hem de situar la seva capacitat de competir, en el millor dels sentits del concepte, amb els instituts públics i privats dedicats exclusivament, o quasi, a la investigació. És obvi que la falta de permeabilitat i sinergia suficient entre centres $\mathrm{i}$ instituts (CSIC, CREA-ICREA, Ikerbasque...) i universitats i la dramàtica situació de les plantilles universitàries decanten clarament la balança cap a les institucions de recerca. En el cas de Catalunya el model d'I+D+I inicia el 2001 un nou enfocament que ha comptat amb alguns èxits destacables. No obstant això, sembla que aquest model, unit a les polítiques universitàries dels darrers anys, porti a un allunyament en el clàssic binomi universitat-recerca. Efectivament, la investigació queda cada cop més en els instituts de recerca, mentre que els fons universitaris per aquest concepte van disminuint.
D'una manera molt general, aquest és el panorama en el qual s'insereix el nostre tema de debat. No és estrany, doncs, que es presentin enfocaments molt diferents, que, tot i la seva multiplicitat, no arriben a abastar la totalitat de la qüestió. No obstant això, el conjunt d'aportacions que presentem tot seguit donen una idea general del sentir i el pensar dels arqueòlegs davant una situació que, tant si és vista des dels instituts de recerca com si ho és des de les institucions universitàries, es percep com a crítica.

4. Tants cops s'ha repetit una obvietat, que la universitat ha de canviar ( $\mathrm{si}$, com totes les institucions de la nostra societat, no ho fes així, encara estaríem impartint el trívium i el quadrívium), que ja hem oblidat l'essencial: és la direcció del canvi que s'està adoptant la més indicada per continuar aportant riquesa en tots els sentits, no solament l'econòmic sinó també el social? 


\section{Arqueología como ciencia de guerrilla}

\author{
Felipe Criado-Boado
}

\section{Introducción}

En lo más agudo de la actual Gran R (que admite la doble lectura de Recesión o Robo), adopté como pie de firma una cita innominada que ora "somos más peligrosos haciendo ciencia de guerrilla que Big Science". Para responder a la invitación de la RAP a participar en este debate me viene bien explicar rápidamente qué sentido otorgo a esa cita. Al hacerlo, me voy a mover desde un análisis más radical a uno más sosegado. Me moveré desde un hipercriticismo del sistema de investigación actual, a una propuesta muy liberal (en genuino sentido norteamericano) para terminar en una posición más equilibrada. Podría haberlo hecho en sentido inverso. En realidad no importa porque los siguientes comentarios se deberían tomar de forma integrada, unos apoyan a otros y necesitamos a todos juntos (habría que añadir irónicamente que cualquier semejanza con la actual situación de la izquierda en España es mera coincidencia).
El punto de partida, el diagnóstico crítico que apunto, y el de llegada, una profundización transformadora de la morfología actual del sistema de I+D, se basan en la experiencia que he reunido en temas de estrategia y política científica (como responsable de grupo de investigación, director de instituto, coordinador de área en el CSIC, gestor de programas de cooperación internacional o más recientemente trabajando para asociaciones internacionales), unas funciones que han sido una extensión de los servicios que como investigadores y servidores públicos tenemos que cubrir. Pero sobre todo se basan en la actual crisis del sistema público de ciencia creada por la gestión conservadora del cambio de época en el que nos hallamos inmersos, y que reconfigura también la naturaleza y función mismas del sistema de producción de conocimiento. Por gestión conservadora no solo me refiero a las estrategias neoliberales, sino también al populismo de derechas y a lo que desde la victoria de Trump se reconoce abiertamente como el progresismo neoliberal (en el sentido que a la etiqueta le ha dado Nancy Fraser).

\section{Superar nuestros problemas...}

Los y las investigadoras somos culpables de varias cosas. Las y los arqueólogos también. No me referiré ahora a la ruptura de puentes con las sociedades y comunidades a los que nos debemos. Tampoco a 
nuestra incapacidad para defender la dignidad de la ciencia en unos años en los que la ciencia española, cuando estaba a punto de operar el gran salto a la primera liga mundial, retrocedió a los niveles de muchos años atrás (ahora, después de una clara recuperación en los últimos ejercicios, estamos todavía presupuestariamente hablando en los niveles de 2006: 6.500 M€ aproximadamente). Tampoco al hecho de que el crecimiento de recursos de los dos últimos ejercicios presupuestarios se debe más al hacer de la Secretaría de Estado de Investigación que a nuestra capacidad reivindicativa. Y ni siquiera me referiré al hecho de que, por las condiciones de rigor y centralización que impone el Ministerio de Hacienda al gasto público, un alto porcentaje de los presupuestos del 2016 de la Secretaría de Estado de Investigación, Desarrollo e Innovación, hayan quedado sin gastar (según un informe de COSCE este porcentaje ha estado desde 2011 por encima del 42\% pero en el 2016 llegó a la cifra récord de 61,5\% como consecuencia de la orden de adelanto de cierre de ejercicio a 20 de julio). Esos son aspectos que se pueden discutir pero que no son el tema a tratar, que es más general.

Somos culpables de contribuir a mantener una gran mentira, la mentira de que el sistema de ciencia funciona normalmente. No es así, y algún día tendremos que despertar de este sueño. Aunque esto suena un poco exagerado, empezaré por comentar esta primera idea.

La impresión que muchos comparten hoy en día es que la evaluación científica ya no funciona como debería. Cuando las marchas por la ciencia en Washington que dieron la bienvenida a la presidencia de Trump, una pancarta popularizada por los retweets decía: "What do we want?" Y se contestaba "Evidence based science". Y volvía a preguntar: "When do we want it?". Y contestaba: “After peer review”. Pues algo no funciona con la evaluación por pares si hay que defenderla con pancartas, mientras que al mismo tiempo Science recoge el 24 de mayo de 2017 la noticia del perro que se coló como miembro de los consejos editoriales de siete revistas médicas internacionales, en Rusia se inaugura el 26 de mayo de 2017 el primer monumento al "peer review", evento que fue noticia del número de Nature de fines de ese mes (la arqueología de la monumentalidad y los memoriales sabe que demasiado a menudo se materializa la memoria cuando esta afloja), y el Times Literary Supplement se pregunta el 24 de octubre de 2017 "the end of an error?” en relación con el peer review.

La impresión detrás de la impresión anterior es que el peer review en revistas está perdiendo en parte su razón de ser. Esta tendría que ser garantizar la aceptabilidad por la comunidad de especialistas de cualquier nueva aportación e incrementar la calidad de todo lo que se publica a través de una discusión constructiva. Pero se ha convertido en un sistema que sanciona aceptaciones o rechazos para defender el statu quo de unos oligopolios editoriales que hacen negocio privatizando el acceso a resultados de investigación generados en su mayor parte con fondos públicos, y utilizando para ello el trabajo gratuito de miles de editores y revisores que son retribuidos con el privilegio de mantener la hegemonía del revisor. Honestamente, ¿cuántos de nosotros como autores o, más sinceramente, como revisores no hemos visto utilizar ese poder para requerir al autor que cite algún trabajo de un compañero, discípulo o de uno mismo, o incluso para reducir la competencia en el mundo de la prioridad de las ideas y la innovación ralentizando la publicación de trabajos competidores? Este problema se solventaría con más trasparencia, trabajando realmente en abierto. Simplemente aplicando la sencilla norma de que la evaluación científica sea nómina, como hacen algunas revistas, el proceso mejora. Mejora aún más si el proceso, en vez de ser un tour entre el accepted o el rejected, fuese un sistema de comentarios abiertos que enriqueciese el trabajo original y dialogara abiertamente con él.

Pero es igual, porque solucionado ese problema, aún queda otro más central. El sistema de peer review no funciona con porcentajes de éxito bajos, por debajo de porcentajes del $30 \%$ o a lo sumo el $20 \%$. Esto es así independientemente de que hablemos del índice de éxito en revistas, o en consecución de proyectos y financiación. El proceso de decisión, como sabemos, no es perfecto, simplemente es el menos malo. Por ello funciona bien con tasas de éxito normales (30-45\%) porque entonces el mayor porcentaje de oportunidades corrige las disfunciones del sistema. Pero situados en bajos umbrales de éxito, el gran problema que el peer review no soluciona es cómo se puede pasar del 30\% de proyectos excelentes que, normalmente, concurrirá a cualquier convocatoria, al $6 \%$ que se aprueba. Es difícil pensar que no pesen las circunstancias corporativas y personales. Algunos sugieren que la forma más justa pero extrema de pasar del 30 al 10\% es echándolo a suertes. La consecuencia es obvia, el decremento dramático de los índices de éxito derivado de las políticas de recortes de dinero público en ciencia, están demoliendo el propio sistema de revisión por pares.

Mientras tanto, mientras decidimos seguir creyendo en el sistema, este hace lo que le parece, financia la investigación que quiere y dónde y cómo la quiere. Y con ello no me refiero a presuntas arbitrariedades de las agencias públicas financiadoras de la investigación. De hecho podemos presumir que ellas, y los y las gestoras de ciencia, cumplen su trabajo con especial buen empeño y rigor. Me refiero a que la investigación importante, la que de verdad cuenta para el sistema, la que inventa su futuro, está mayormente fuera de la academia. Las industrias de la genómica, los fármacos, los nuevos materiales, el armamento, las TIC y la Inteligencia Artificial, las tecnologías convergentes del complejo NBIC (nano-bio-info-cogno), están principalmente fuera de la academia, o usan a esta de forma tangencial e instrumental. Requieren inversiones multimillonarias, y producen pingües beneficios, pero precisan no solo de volúmenes sino también de formas de capitalización que se escapan al sector público. Precisan también de una investigación que no se puede hacer ni en Modo 1 ni en Modo 2, lo que quiere decir, para abreviar, que no se puede hacer con pequeños grupos que se mueven con parsimonia y tienen todas las ventajas de la libertad del mundo académico público pero ninguna 
de las ventajas de un sector privado que moviliza medios, infraestructuras y equipos gigantescos, aplica sistemas de productividad industrial, no "pierde el tiempo" en publicar papers porque no es eso lo que busca, hace trabajar a sus efectivos con disciplina de empresa, mantiene líneas de producción paralelas sin que se conozcan para cruzar resultados, etc. Datos como que en la última convocatoria de financiación catalana de Grups de Recerca la totalidad de los grupos universitarios hayan recibido un 35\% de la financiación mientras los centros CERCA el 52\%, o que en algunos subprogramas del Programa Nacional de I+D (cabalmente en las áreas de Humanidades), el índice de éxito se aproxime al $70 \%$ pero otorgue auténtica microfinanciación, apunta a una inercia que supone que mientras se financia holgadamente lo que interesa, se apacigua a la totalidad del sistema con una política efectiva de café para todos. Otro modo de construir la gran mentira que citaba antes.

El énfasis en la innovación, la exigencia de que la investigación pública coadyuve al desarrollo industrial y tecnológico, está conduciendo a formas sutiles de privatización de conocimiento público mediante formas de transferencia de tecnología y mecanismos de financiación vinculados a empresas. Lo dice alguien que no se asusta por estas colaboraciones. Hace años me suspendieron una cátedra diciendo como elogio al candidato aprobado lo que el tribunal no se atrevió a decirme a mí como reproche: alabaron la capacidad del candidato para generar recursos sin caer en la trampa neoliberal de venderse a las empresas. Creo que fue uno de los episodios más gloriosos de mi biografía académica. Hacer investigación orientada o a demanda de empresas o socios sociales concretos no es realmente un problema. El auténtico problema es cuando la poca financiación de la que dispone el sistema se pone en forma de proyectos de colaboración con empresas donde la parte universitaria aporta su know-how y lo transfiere a las empresas por una mínima parte de su valor; igual cuando se plantean spin-offs; también se podría hablar aquí de patentes.

Lo peor es que esta gran mentira no creo que sea consecuencia sobre todo de una política consciente. Algunos sacudirán enseguida las palabras mágicas para decir que esto es el resultado intencional de una política neoliberal. No dudo que en la gran escala esto es cierto. Pero cuando nos venimos al análisis de las cosas y procesos concretos, conviene reconocer que la apelación al neoliberalismo no tiene capacidad explicativa por sí misma. A veces es un comodín que limita un auténtico análisis crítico que permitiría encontrar además las causas de lo que nos pasa en posiciones seguidistas, acomodaticias, intelectualmente perezosas y relacionadas sobre todo con las formas de enculturación y subjetivación de todos los actores del sistema. Empezando por los propios investigadores que reproducimos con facilidad unas reglas de juego injustas, anticuadas e insuficientes hoy en día, en la esperanza de que nos beneficien individualmente.

\section{... con ciencia postnormal...}

Frente a todo ello tenemos algunas opciones. En el ámbito concreto de las ciencias humanas (también en gran medida en las ciencias sociales), tenemos opor- tunidades reales. Estas pueden llegar a través de una removilización de nuestras capacidades mediante lo que se puede concebir como una estrategia guerrillera, una ciencia de guerrilla. La arqueología en particular ofrece un ejemplo genuino de estas oportunidades.

Hay muchos ámbitos de investigación (no todos, ciertamente, pero muchos y muy significativos) en los que se puede trabajar con pocos medios. Casi sin financiación se pueden producir resultados que son encima autónomos e independientes, porque cuando accedemos al big funding el peso de los procesos burocráticos (solicitar el proyecto, escribir los informes, preparar las justificaciones, y superar las auditorías y sucesivas alegaciones) te resta recursos, y hace perder capacidades y espontaneidad. Esto es más cierto en una actividad como la arqueología que, a través del vínculo comunitario y de la atracción que ejerce en la gente, encuentra en las colaboraciones de aficionados y en la movilización de trabajo voluntario una gigantesca capacidad de aportación de recursos extra. Esto no va en contra de la defensa de la arqueología profesional, de los profesionales de la arqueología y de los estándares metodológicos de nuestra actividad; es solo reconocer una capacidad adicional que tenemos gracias a que la práctica arqueológica es tangible, posee un carácter romántico, afronta cuestiones que interesan a las personas (desde el territorio y la sensibilidad ambiental incrementada por la preocupación por el cambio climático y la sostenibilidad, a la memoria, la tradición y la identidad), y ofrece asideros físicos (yacimientos, materiales, paisajes) para generar narrativas concretas que tienen mayor poder evocador que las abstractas de la ciencia y la historia.

Trabajar en modo de proximidad, lo que más técnicamente se denomina ciencia pública, comunitaria o postnormal, tiene un recorrido posible e interesante. Pero tiene otras implicaciones que surgen cuando nos tomamos en serio las dos partes de la ecuación, que hacemos ciencia y que la hacemos en la arena pública. Un tema a cuestionar es el de la excelencia científica. La pretensión de excelencia es el Grado 0. Pero no es el punto de llegada. No se puede aceptar la excelencia científica por la excelencia. Pero tampoco se puede aceptar el reduccionismo simplista inherente a oponer excelencia a relevancia del conocimiento, que muchas veces es otra manera de intentar negociar el dilema entre hacer investigación fundamental o consultoría experta. Es un lugar común que no hay investigación excelente que no tenga valor social, ni hay conocimiento experto que tenga valor real si no es innovador y tiene un nivel propio de excelencia.

La medida de la excelencia es complicada. Hay que apelar a que el impacto no son solo citaciones. Hay otros impactos. Su aritmética es compleja porque todavía no hay una lista consensuada de cuáles son esos impactos. Esto da la razón a los especialistas en cienciometría que reconocen cada vez más el valor de medir el impacto (el iH por ejemplo) desde Google Scholar y no solo desde Scopus o WoK, porque la primera registra las citaciones de mucha gente, no solo los propiamente científicos, y lo hace rastreando cualquier medio de publicación, no solo un elenco restringido de revistas. 
Igualmente hay que reconocer lo mentiroso, casi falaz, que es mantener la captación de recursos como un criterio de excelencia. Este servía cuando se podían captar recursos con normalidad. Pero es casi enternecedor mantener el criterio cuando no hay recursos que captar. De nuevo es una idea que toma cada vez más fuerza en la bibliografía crítica internacional.

Una parte básica de esta estrategia radical es viabilizar la liberalización de todo el conocimiento producido con medios y financiación pública. No se trata de reservarlo para transferirlo-cederlo a empresas concretas, sino de buscar un medio para hacerlo trabajar socialmente, que permita que pueda ser apropiado por cualquiera. Plantear esto se carga la política de declaración y licenciamiento de patentes, lo que a su vez tiene un coste tremendo para cualquier país. Pero, al margen de que incluso esto se puede revisar (un buen ejemplo es lo que pasa con las medicinas genéricas y el beneficio social que tiene trabajar esencialmente a partir de patentes ya liberadas), yo estoy hablando aquí de Humanidades y Arqueología, áreas de conocimiento en las que no se patenta nada.

La clave de esto es cómo hacer el conocimiento accesible. Para ello no llega con el acceso abierto a los resultados de investigación. La auténtica apropiación social del conocimiento es ciertamente algo más complejo que colgar $\mathrm{PDF}$ en un repositorio público. El movimiento por el acceso abierto desde la Declaración de Berlín de 2003, ha inaugurado una época más compleja y rica. Los 15 primeros años sirvieron para otorgar en el teatro de la ciencia un rol principal al libre acceso a los resultados de investigación. Pero en los próximos 15 años tenemos que construir un open access radical. Ahora mismo se demanda cada vez más el acceso a los datasets y datos brutos del proceso científico. Cada vez es más fuerte el movimiento que exige que estos estén disponibles para que las publicaciones entren en proceso de revisión editorial. Detrás de esto uno piensa que se oculta la última estrategia de los grandes holdings de publicación científica para potenciar sus sistemas online, bajo pago, y privatizar así la mayor parte de los resultados de investigación. Pero hay formas de responder a esta demanda (que es muy lógica) de los procesos de revisión editorial utilizando repositorios públicos institucionales (el de mi institución $<$ digital.csic $>$, tiene una función específica para colgar y guardar datasets y mantenerlos embargados mientras el artículo está en revisión, solo accesible para los revisores). Esto es algo que en arqueología tiene una importancia básica y que nunca hemos sido capaces de solucionar plenamente porque la publicación (i.e. el hacer públicas) de las memorias arqueológicas, y el acceso a todo el registro arqueológico producido, sigue siendo algo pendiente.

Pero el open access radical va mucho más allá. Lo que hace falta es trabajar en abierto. No solo haciendo plenamente accesibles los resultados, sino el proceso. Y no solo sometiendo este al escrutinio público permanente, sino haciendo al público parte activa del proceso, pasando a procesos de co-construcción del conocimiento y el patrimonio entre arqueólogos y especialistas y agentes sociales diversos. Si alguien me pregunta cómo hacerlo, creo que no hay aún medidas universales, pero mi impresión es que estos temas van a ocupar cada vez más la agenda científica de los próximos años.

Todo esto es lo que está detrás de la cita que anoté al empezar. Los modos y medios de la ciencia activista, de la investigación-acción, serán cada vez más hegemónicos y marcarán las pautas que la big Science tendrá que adoptar en el medio plazo. Aunque esta sea controlada por holdings esencialmente privados y grandes intereses económicos, el universo de agentes produciendo ciencia es tan amplio, que no puede ser controlado. En el peor de los escenarios, tendremos a Wallace y Tyrel de un lado, y a Doc Badger y Hannibal Chew del otro (me refiero a las versiones 2049 y original de Blade Runner). Además, a la mayor parte de las líneas de investigación de las humanidades y ciencias sociales no les afecta esa orientación porque esos intereses son ajenos a ellas. Vaya, la big Science ni sabe que existimos, tiende a negar nuestra existencia, y esto es un pecado de hybris que le pasará factura.

En este sentido hay un dato muy relevante para empoderarnos de nuestras capacidades, tanto como de nuestras obligaciones: el profesorado de humanidades en las universidades españolas totalizaba 11.694 personas en 2006. Si agregamos el profesorado de ciencias sociales, la cifra llegaba a 37.960, el $44 \%$ del total del profesorado universitario español (según datos del Libro Blanco de la Investigación en Humanidades realizado por FECYT). Dada la trayectoria de las ofertas de empleo no creo que esta cifra haya cambiado mucho, a pesar de que las jubilaciones masivas marcadas por el calendario afectarán a partir de ahora a estos números (añadiendo la generalizada amortización de plazas y el bajo nivel de nuevas contrataciones, se podría pensar que alguien se ha planteado hacer la reconversión de nuestras áreas con el calendario en la mano y sin tener que aplicar medidas que inevitablemente encienden la respuesta popular). Aunque una elevada proporción de esta masa de especialistas no está totamente activada en investigación, sigue siendo una altísima nómina de expertos. Es imposible que entre todos ellos no surjan algunas ideas nuevas, avaladas por procesos de investigación originales, que conduzcan a la emergencia de nuevos paradigmas con capacidad para modificar nuestros modelos de comprensión de la realidad y por ende el propio sistema social. Nuestro auténtico problema sería que no fuera así. Pero creo sinceramente que no tenemos ese riesgo. Véase por ejemplo el poder transformador que tiene en la arqueología, y por extensión en lo político, el reciente giro hacia la memoria histórica y el pasado contemporáneo en la investigación arqueológica, algo que se ha hecho esencialmente al margen de la arqueología académica y consolidada, pero que está ahí, nadie lo puede negar y está generando efectos transformadores de la disciplina.

\section{... y con ciencia normalizada}

Nada de lo que he dicho antes son razones para estar en contra de la revisión por pares, la publicación 
en revistas indexadas, el big funding, los grandes proyectos e infraestructuras científicas, la arqueología (o las humanidades) hechas con medios de las ciencias naturales y las tecnologías digitales. En realidad, un sistema transformador de las condiciones normales requiere cumplir antes con estas.

Si algo nos ha enseñado la crítica simultánea del positivismo y de los excesos relativistas y subjetivistas posmodernos, es que necesitamos reivindicar la construcción de una nueva objetividad científica (como complementaria de otras formas de racionalidad y conocimiento más especulativas, narrativas, retóricas, performativas y artísticas) que nos permita oponernos a la irracionalidad interesada de los movimientos alt-right, pero que no podemos hacerlo simplemente reificando una creencia acrítica en los modelos de ciencia positivista construidos por la modernidad, y que están ellos mismos cruzados por intereses corporativos no visibles. Para ello hay muchas soluciones, pero yo apelaría, en el contexto de este texto, a mantener un sistema de investigación basado en un modelo de ciencia débil fortificada por la normalidad del sistema. El modelo que hoy podemos reconocer lo he denominado en otros sitios Ciencia $3 R$ : conocimiento científico basado en datos rigurosos, metodologías replicables y modelos teóricos robustos. Lo que fortalecerá a ese modelo no es la confirmación de hipótesis por el método hipotético-deductivo o el descubrimiento de leyes universales (cosas que no son factibles en muchos campos de investigación, sobre todo en los nuestros). Será el mantenimiento de las condiciones formales del sistema de ciencia que garantizan la aceptación de las nuevas propuestas por una comunidad desinteresada y la construcción de redes de confiabilidad en los resultados de la investigación por parte de diversos actores sociales. La publicación en medios con sistemas acreditados de control de calidad, el peer review, la evitación de conflictos de intereses, el acceso abierto a los resultados, la investigación orientada a problemas y no disciplinarmente, la transdisciplinariedad, el diálogo de saberes, y la apropiación fuerte del conocimiento, son instrumentos básicos del sistema de ciencia débil que propongo.

Desde mi perspectiva, la normalización del sistema de ciencia en España requiere también una transformación institucional que está pendiente desde hace tiempo. El gran salto de calidad de la ciencia española se dio desde finales de los años ochenta a través de los Planes Nacionales de Investigación y la financiación de proyectos. Pero este sistema de financiación solo orientado por proyectos se ha quedado corto. Se ha ido completando con nuevos instrumentos de financiación basal a grupos de investigación, bien implementados desde la Administración General (convocatorias Severo Ochoa y María de Maetzu para grandes grupos de investigación), o articulados por las autonomías (particularmente Catalunya, Euskadi, Galicia, Madrid y Andalucía, aunque el sistema andaluz se aminoró hasta su casi desaparición durante estos años de crisis). El sistema ha ido creciendo hasta generar contradicciones disfuncionales, pues mientras la financiación de proyectos tiende a fisurar las capacidades de consolidación de masas críticas estables, los mecanismos de financiación a grupos se basan en su consolidación. Pero, sobre todo, el hecho de que en las universidades la lógica reivindicación de mantener la función investigadora haya llevado a seguir dejando esta en manos de los departamentos, convierte a estos en agregados informes que no pueden competir con los centros o institutos de investigación que tienen identidad estratégica y capacidad total para definir su propia política científica. Este proceso se va a exacerbar por la reciente reestructuración de departamentos universitarios en grandes departamentos que serán incapaces de tener una política científica común y dejarán esta en manos de los equilibrios de poder dentro de los departamentos. Donde mejor se observan las contradicciones que aquí afloran es en las dificultades de muchos departamentos para acoger con normalidad plazas ICREA (en Catalunya) o Ramón y Cajal (en todo el Estado).

Lo que necesita el sistema en su totalidad (quiero decir, en el conjunto de la investigación que se hace en España sea en ámbitos universitarios, de OPI o institutos de investigación, o incluso centros tecnológicos y fundaciones públicas o privadas) es una cartografía organizativa de su base totalmente nueva, que transfiera todo el poder de organización de la investigación a los Grupos de Investigación y genere después un sistema de incentivos (a través de las convocatorias de financiación) para (sucesivamente) consolidar los grupos, estimular el crecimiento de su masa crítica y agrupar a los más dinámicos de ellos en agregados mayores. Lo importante es que el grupo sea el rector principal de su orientación y estrategia científica, se le dé la oportunidad de marcarla y de ser evaluado por ello. Solo de ese modo un grupo universitario podrá competir en condiciones de igualdad con los grupos de centros que tengan una estructura como los CERCA, que todos querríamos para nosotros. Personalmente a mí no me molesta que haya centros CERCA, CSICs vascos o Severo Ochoa. Cuantos más tuviera el país, mejor sería para todos dados los beneficios sistémicos que siempre tiene la consolidación de un sistema vertebrado. Lo que me molesta es no poder competir en las condiciones que ellos compiten.

No es difícil articular una transformación de este tipo. Sobre todo porque creo que el sistema y sus actores están maduros para ella ya que a estas alturas todos notamos que la situación se hace insostenible a medio plazo y que necesitamos implementar soluciones urgentes.

Pero mientras llega esa posibilidad, acabaré insistiendo en que nada hace mayor mal a las Humanidades y a la arqueología que reivindicar su aparente excepcionalidad para demandar, en el fondo, tratos de favor y diferenciados respecto a lo que es normal en el sistema de ciencia e investigación. No hay disciplina o comunidad científica que no sea especial a su modo. Pero todos compartimos algunas cosas básicas. Reconocer esto forma parte de un necesario rearme de la pretensión de objetividad en una época de la historia humana en la que predominan las fake news y se disuelve el carácter positivo del conocimiento experto porque este frena las pretensiones manipulativas crudas de agentes sociales privilegiados. Y nada hay 
que haga prever que esto vaya a cambiar en el corto plazo; las inversiones de capital privado conservador en agencias de desinformación (como Breitbart) y en instrumentos tecnológicos para instrumentalizar las redes sociales (como es el engendro Cambridge Analytica - que se publicita sin rubor bajo el lema "uses data to change audience behavior", y sin la cual seguramente no habría habido triunfo del Brexit, Trump o PP en las últimas elecciones españolas). Situados ante este contexto, es privilegio nuestro no hacer los cambios necesarios porque queramos seguir manteniendo nuestras diminutas áreas de beneficio. Pero frente a ello prefiero pensar que la arqueología tiene muchas capacidades para repensar el futuro, pues a fin de cuentas es una disciplina que estudia nuestros futuros pasados, y está excepcionalmente dotada para comprender cómo el futuro llegó a existir. Y volviendo a la temática de este debate, también tiene la capacidad, por su función de puente entre las ciencias humanas, las sociales, las naturales y las duras, por su función agregadora en proyectos transdisciplinares complejos, de diseñar y naturalizar una vertebración distinta de la función investigadora, consecuente con los retos que nuestras sociedades enfrentan.

Felipe Criado-Boado Instituto de Ciencias del Patrimonio, Incipit

CSIC

Avda. de Vigo s/n

15705 Santiago de Compostela

felipe.criado-boado@incipit.csic.es

\section{¿Por qué la}

arqueología en España necesita un nuevo modelo universitario?

\section{Juan Antonio Quirós Castillo}

Aunque el nivel de reflexión y autocrítica de la arqueología en España ha aumentado de forma significativa en los últimos años (por ejemplo Díaz del Río 2000; Criado 2010; Vigil-Escalera 2011; Almansa 2011; Canosa 2014; Cau 2015; Vaquerizo 2015, 2016; Ruiz Zapatero 2016), tengo la impresión de que no se ha aprovechado el crudo escenario de la crisis actual para hacer una evaluación en profundidad de las principales disfunciones de nuestra disciplina, especialmente en el ámbito universitario. No cabe duda de que la mayor parte de los principales trabajos críticos son pesimistas y trazan cuadros plagados de incertidumbres que contrastan notablemente con otros diagnósticos, como el realizado en el Reino Unido (Barker et al. 2017). En el fondo, buena parte de los académicos siguen esperando que se supere la crisis, vuelvan a llegar más recursos y puedan volver a hacerse las cosas como antes. Pero los problemas estructurales de la arqueología académica, ¿se deben atribuir únicamente a una cuestión de financiación y de recursos, o bien de modelo universitario y contexto social (Hernando 2002)? Ciertamente la progresiva afirmación del modelo universidad-empresa y estudiantes-clientes que ha tenido lugar en los últimos decenios requiere una reflexión que supera los límites de estas breves notas (Ordine 2013).

El año 2007 marca un doble punto de inflexión en el sector académico universitario español como consecuencia de la implantación de la vía española del denominado modelo de Bolonia (Azcárraga 2015) y, por otro lado, por el duro impacto que ha tenido la crisis económica en la práctica de la arqueología hispana que se ha traducido, en palabras de D. Vaquerizo, en una 'arqueología para un futuro incierto' (Vaquerizo 2015). El primero de los hitos ha permitido alcanzar una vieja aspiración de la arqueología española (Querol 1998; Ruiz Zapatero 2009): contar con una titulación propia. El segundo de los escenarios ha mostrado las debilidades estructurales de la arqueología en nuestro país. Pero además ha permitido visibilizar como nunca los anillos más débiles de la cadena arqueológica, y en particular el de los profesionales empleados en la arqueología comercial, representados de la forma más dramática posible en estos trabajos (Parga 2012). También se ha puesto el acento sobre la responsabilidad de las administraciones en un contexto marcado por la ausencia de una verdadera política arqueológica (Ruiz Zapatero 2016), aunque seguramente ha habido menos reflexión en torno al ámbito museístico y académico. Pero después de diez años ya hay una cierta perspectiva para valorar los efectos de estos dos procesos.

Si hay algo que comparten todos los colectivos arqueológicos es su formación universitaria. El papel tractor de la universidad a la hora de formar nuevos profesionales, pero también de construir nuevos escenarios intelectuales para la renovación y actualización de la práctica arqueológica merece una reflexión reposada, amplia y profunda. Y aunque no han faltado en los últimos años propuestas y reflexiones acerca de aspectos como la formación universitaria, el doctorado, los procesos de selección del personal o la carrera investigadora (Hernando, Tejerizo 2011; González Ruibal 2011; Ruiz Zapatero 2010, 2015), no se ha entrado de lleno a valorar las limitaciones reales que impone el modelo universitario actual a la hora de superar las disfunciones que afectan a la investigación y la formación universitaria.

En este texto se pretende argumentar que es preciso una importante reforma del modelo universitario hispano conceptualizado en otra etapa de nuestra historia y que, a forma de un yacimiento muy antiguo, ha ido recibiendo parches, normas, leyes y reglamentos que se han ido estratificando y ocultando el fondo de los problemas. Y de la misma forma que las hechuras del contrato social surgido de la transición siguen estirándose y parecen romperse cada día por muchos sitios, desde mi punto de vista la universidad en España precisa de una reforma profunda en una dirección de flexibilización y corresponsabilización de los agentes implicados en 
la investigación, transferencia y formación. Teniendo en cuenta la complejidad de la temática, centraré mi atención en esta ocasión únicamente en tres ejes muy concretos: el sedentarismo académico y la autonomía universitaria; la organización académica de la arqueología en las universidades españolas; la organización de la investigación en la universidad. Y aunque muchos de estos aspectos afectan a la mayor parte de las disciplinas universitarias (Azcárraga 2011), su peso es muy marcado en el caso de la arqueología académica.

\section{El sedentarismo académico, la promoción de los mejores y la autonomía universitaria}

Una de las principales anomalías de la universidad española respecto al panorama europeo es el inmovilismo del profesorado, resultado perverso de una serie de circunstancias y decisiones tomadas durante la transición. La universidad postfranquista desarrolló el concepto de autonomía universitaria con el fin de acabar con el intrusismo del régimen anterior en las instituciones de enseñanza superior, así como vincular el desarrollo de las universidades a las nuevas comunidades autónomas que vertebran el modelo estatal del 78. Pero la noción de autonomía universitaria ha terminado legitimando intereses corporativos (Azcárraga 2015: 28) y políticas universitarias localizadas y cortoplacistas que han limitado la capacidad de renovación intelectual de las universidades.

Uno de los efectos más perversos del concepto de autonomía universitaria es que ha servido para diseñar jaulas doradas en las que encerrar personas, pero no para diseñar marcos de innovación. La obtención de una plaza de funcionario en la universidad española está vinculada a un perfil temático delimitado en forma de áreas de conocimiento en un departamento concreto. A diferencia de lo que ocurre con otros puestos en la administración pública, el profesorado universitario funcionario no puede transferirse a otra universidad a no ser que se supere otro concursooposición (en las circunstancias en las que se celebran estos concursos en España). En el Reino Unido o en Estados Unidos es impensable que un estudiante se gradúe en una universidad, realice el doctorado en esa misma universidad, obtenga una plaza primero precaria y luego estable en esa misma universidad y se jubile en la misma universidad. En España esta es la norma. Francia, Italia y la mayor parte de los países de nuestro entorno cuentan con mecanismos de movilidad del personal universitario que permiten, en función de las ambiciones, estímulos y retos de los gestores universitarios y de los propios profesionales, re-construir cíclicamente los marcos formativos e investigadores. También cuentan, con frecuencia, con mecanismos más flexibles y con más recursos que en España a la hora de poder contratar investigadores jóvenes e innovadores capaces de renovar la academia.

Nuestro modelo normativo garantiza, en teoría, la publicidad de los mecanismos de contratación, la igualdad de oportunidades mediante acreditaciones nacionales y el rigor de los procedimientos de selección. Pero más allá de la normativa, A. González
Ruibal no ha dudado en señalar que "los males de la arqueología académica española... en última instancia son reducibles a un solo problema: la corrupción generalizada del establishment académico" (González Ruibal 2011). Según este autor, los intereses espurios de los propios académicos determinan que no siempre sean los mejores los que llegan a la universidad, o que determinadas facciones sean las que orienten el discurrir de la academia más allá de la meritocracia. Aunque A. González Ruibal considera que la única solución a este problema pasa por retirar competencias al establishment académico, en cambio creo que una mayor corresponsabilización y participación de los académicos en proyectos ambiciosos que favorezcan la diversificación universitaria y la sana competencia sea una parte importante de la solución. Si el futuro de un departamento o de un puesto de trabajo dependen de la capacidad de mejora e innovación del colectivo académico responsable y no de una decisión administrativa o política externa, quizás las cosas serían algo distintas.

Solo un puñado de universidades cuentan con un número amplio de profesores especializados en arqueología prehistórica y clásica, raramente en época medieval o en períodos más tardíos, siendo mayoría los centros en los que solo hay el número suficiente de docentes para que algunas asignaturas estén presentes con el fin de garantizar universidades generalistas y uniformes. Solamente posibilitando un modelo universitario más dinámico, especializado y antiendogámico será posible romper esta rutina y garantizar la creación de departamentos, institutos y centros universitarios más sólidos, abiertos y atentos a los contextos sociales en los que intervienen.

\section{La organización académica de la arqueología en las universidades españolas}

Resulta paradójico constatar que las titulaciones de arqueología han llegado a las universidades (grandes) en España cuando menos falta hacía. Es decir, cuando se había producido la contracción del mercado comercial, investigador y divulgativo en el ámbito de la arqueología. Es frustrante observar la dificultad que ha tenido y sigue teniendo la universidad española para adaptarse en tiempos cortos a las necesidades sociales incluyendo nuevas titulaciones, asignaturas, especializaciones o itinerarios. El alto grado de burocratización y de autorizaciones que implica la creación de nuevos títulos, los intereses académicos-corporativos locales y las inercias generadas constituyen un freno fundamental para que la universidad desarrolle adecuadamente sus funciones y sea capaz de satisfacer las demandas que se generan en su entorno social. O generar otras nuevas.

Basta, por ejemplo, observar el liderazgo que investigadores españoles tienen en congresos internacionales (como los de la European Archaeological Association) en temáticas totalmente extrauniversitarias como son la arqueología de las sociedades modernas y contemporáneas, la arqueología postcolonial, las prácticas de patrimonialización, la arqueometría o ciencias arqueológicas, etc., para darse cuenta del 
desfase que existe entre formación e investigación, entre las inquietudes de las generaciones jóvenes de arqueólogos y la academia establecida. Me pregunto si habrá en los próximos veinte años una asignatura dedicada a la Arqueología de la Guerra Civil en alguna universidad española. Sin duda, tesis doctorales, trabajos fin de máster y trabajos fin de grado ya los hay o los habrá muy pronto.

Esta rigidez tiene, además, graves consecuencias en lo que se refiere a la necesaria conexión entre transferencia, investigación y formación. El creciente nivel de autoconciencia teórica de la arqueología académica en España choca con un sistema de organización académica que, en mi opinión, es cada vez más anacrónico. Resulta sorprendente, en un mundo académico e investigador cada vez más regido por temáticas, metodologías o enfoques teóricos que exploran procesos transversales como son la complejidad social, la alimentación, las formas de desigualdad, la arqueología política, etc., constatar que la universidad siga manteniendo separadas en dos áreas de conocimiento distintas la Prehistoria (695) y la Arqueología (033). Y dentro de la Arqueología (histórica) el abismo entre la Arqueología Clásica y la Arqueología Medieval sigue siendo la norma. A su vez, los arqueólogos de la Edad Media se encuadran en áreas de conocimiento de Arqueología (033) o de Historia Medieval (485). Los arqueólogos de las sociedades modernas y contemporáneas ni están, ni se les espera. Esta compartimentación resulta siempre difícil de explicar a los colegas que vienen de otros países en los que la norma es la convivencia en departamentos comunes (por ejemplo, el Reino Unido) o bien donde los investigadores están adscritos a disciplinas más circunscritas dentro de cualquier departamento (por ejemplo, en Italia o en Portugal) o forman parte de grupos de investigación mixtos (como suele ser frecuente en Francia).

La arqueología del siglo XXI es una disciplina en transformación que no encuentra fácil acomodo en sistemas académicos tan compartimentados como los actuales, por lo que sería preciso, también en este campo, combatir el exceso de regulación para favorecer una mayor experimentación académica. Sigue siendo inconcebible que la enseñanza de la arqueología sea un grado no experimental. Sigue siendo inconcebible que la universidad no sea un factor de innovación, sino una institución a remolque de las decisiones administrativas y políticas que siguen lógicas conservadoras.

\section{La organización de la investigación de la arqueología en las universidades españolas}

Pero seguramente es el ámbito de la investigación donde se hace más palpable la rigidez de nuestro modelo universitario. Si la formación universitaria es prevalentemente monodisciplinar, la investigación no lo es, y la universidad española no está preparada para este reto. Salvo raras excepciones, en los departamentos de Prehistoria y Arqueología no hay físicos, químicos, botánicos, antropólogos o zoólogos, como ocurre en otros países europeos. Pero es que, a su vez, los físicos, químicos, botánicos, antropólogos o zoólogos que trabajan con materiales arqueológicos en sus respectivos departamentos tampoco tienen vida fácil. El déficit estructural de "arqueómetras" en la universidad española es realmente llamativo, y esa es una de las razones por las que haya tan pocos laboratorios especializados en nuestro país.

En los últimos tiempos esta situación se va corrigiendo puesto que la especialización "arqueométrica" o técnica que permite participar — de forma más o menos intensa - en el estudio de materiales y registros de múltiples yacimientos produciendo decenas de artículos, es premiada cada año en las convocatorias públicas del Programa Estatal de Promoción del Talento y su Empleabilidad en I+D+i. Y aunque es preciso corregir el déficit histórico de "arqueómetras" y especialistas en bioarqueología, geoarqueología y otras temáticas en las universidades, la viabilidad de otros perfiles arqueológicos más "convencionales" o especializados en temáticas como la arquitectura, la cerámica u otros temas de larga tradición, se ve comprometida en los procesos de selección. Esto ocurre también, porque las comisiones de evaluación se han acostumbrado más a contar artículos que a evaluar en sentido propio las aportaciones y sus contenidos. De hecho, la extensión de los currículos de los investigadores españoles sigue siendo difícil de explicar a los colegas europeos, teniendo en cuenta que es perfectamente factible obtener una plaza permanente en una universidad británica con un número reducido de excelentes trabajos.

El sistema de grupos de investigación que se ha implantado, con mayor o menor éxito en muchas universidades del estado, pretende dar visibilidad, cohesión e identidad a colectivos interdisciplinares que trabajan en el seno de universidades concretas o comunidades autónomas concretas. Por lo tanto, estos grupos reflejan las debilidades y las fortalezas propias de la universidad o las universidades en las que están adscritas en términos de contratación, política científica, flexibilidad e innovación. Al menos en el País Vasco, los grupos están cerrados a los no universitarios, de tal modo que resulta imposible incluir de forma orgánica a las empresas de arqueología que, a pesar de todo lo que han padecido, siguen siendo la principal fuente de arqueología primaria en nuestro país. Esta falta de flexibilidad es causante de muchas ocasiones perdidas a la hora de crear formas más inclusivas y socialmente incisivas de arqueología.

Por último, es preciso definir una carrera investigadora flexible, en la que haya puestos de investigadores similares a los que ICREA e IKERBASQUE han creado en Cataluña y en el País Vasco respectivamente. No debería de ser una tragedia que durante un año no se impartiese una asignatura porque un profesor ha obtenido una licencia sabática. Así es como se escriben muchos libros en otros países europeos. Debería de ser sencilla la transferencia entre el CSIC, ICREA, IKERBASQUE y las universidades, aunque fuese a tiempo determinado. Y, sobre todo, debería de darse más espacio a las generaciones jóvenes, las mejor preparadas de los últimos decenios, que ven como sus esperanzas y ambiciones quedan cercenadas por un sistema inadecuado. 
En definitiva, contamos con un modelo universitario que infantiliza a todos los colectivos implicados, sometidos a complejos mecanismos de control y de burocratización de la práctica docente e investigadora. Los nuevos y engorrosos mecanismos de control y auditorías de los proyectos de investigación del Plan Nacional —aplicados con plazos imposibles, cambiando en ocasiones las normas de aplicación respecto a las concesiones originales y culpabilizando a los investigadores hasta que demuestren lo contrarioes solo uno de los perversos resultados de lo que ha ocurrido en la última década. Lo mismo podía decirse de la forma en que se ha implementado el sistema de Bolonia (Azcárraga 2015). Pero además, el modelo universitario actual es demasiado poco flexible a la hora de actualizar los itinerarios formativos, de incorporar nuevas especializaciones y de construir equipos multidisciplinares en los que experimentar la transdisciplinariedad. Como consecuencia de ello, la conexión entre sociedad civil y universidad se desvanece.

Si la universidad no es capaz de transformarse profundamente, entendiendo que es una institución al servicio de los ciudadanos y no de intereses académicos o de grupos de poder específicos, será el CSIC, algunos institutos de investigación — tal y como está ocurriendo en Cataluña-, u otras instituciones los que terminen capitalizando la innovación y la investigación en arqueología. Este es quizás el principal reto al que se enfrenta la arqueología académica en los próximos años.

\section{Juan Antonio Quirós Castillo Catedrático de Arqueología, Departamento de Geografía, Prehistoria y Arqueología Universidad del País Vasco / Euskal Herriko Unibertsitatea Paseo de la Universidad, 5, 01006 Vitoria-Gasteiz quiros.castillo@ehu.es}

\section{Bibliografía}

Almansa, J. (ed.) (2011). El futuro de la Arqueología en España. Madrid.

Azcárraga, J. A. (2011). Universidades manifiestamente mejorables. Claves de Razón Práctica, 209: 36-44.

AzcárRaga J. A. (2015). ¿Universidades boloñesas 4+(máster) o 3+(máster)? ¿Es ésta la cuestión, o una cara más del mismo problema? CIAN-Revista de Historia de las Universidades, 18.1: 21-54.

Barker, G., Roberts, C., Gosden, C., Horning, A., Welham, K. (2017). Reflections on Archaeology. British Academy. London.

Canosa Betés, J. (2014). Arqueología: Para qué, para quién, cómo y por qué. Arqueoweb, 15: 291-334.

Cau Ontiveros, M. A. (2015). Arqueología para un futuro incierto: un debate abierto. Pyrennae, 46.2: 79-87.

Criado Boado, F. (2010). Què és avui l'Arqueologia? Cota Zero, 25: 51-56.
Díaz DE Río, P. (2000). Arqueología Comercial y estructura de Clase. En: M. M. Bóveda López (ed.). Gestión Patrimonial y Desarrollo Social. CAPA 12. Santiago de Compostela: 7-18.

GonzÁlez Ruibal, A. (2011). El desastre académico de la arqueología. En: J. Almansa. El futuro de la Arqueología en España. Madrid: 99-104.

Hernando, A. (2002). Teoría arqueológica y crisis social. Complutum, 23.2: 127-145.

Hernando Álvarez, C., Tejerizo García, C. (2011). La arqueología y la academia del siglo xIX al "Plan Bolonia". Revista Arkeogazte, 1: 53-69.

Ordine, N. (2013). La utilidad de lo inútil. Manifiesto. Barcelona.

Parga Dans, E. (2012). Estructura y desafíos de la arqueología comercial en España. Un proceso de innovación social. Revista d'Arqueologia de Ponent, 22: 87-199.

Querol, M. A. (1998). La arqueología en las universidades españolas. PH: Boletín de Patrimonio Histórico, 22: 15-18.

Ruiz Zapatero, G. (2009). ¿Qué arqueología enseñar en la universidad del siglo xxi? Complutum, 20.3: 225-238.

Ruiz Zapatero, G. (2010). La carrera investigadora en arqueología: una mirada desde la universidad española. Revista d'Arqueologia de Ponent, 20: 242-246.

Ruiz Zapatero, G. (2015). El valor del doctorado en arqueología a comienzo del siglo xxI. Revista d'Arqueologia de Ponent, 25: 349-372.

Ruiz Zapatero, G. (2016). Presente y futuro de la Arqueología en España. Luces, sombras y desafíos. En: Vaquerizo, D., Ruíz, A. B., Delgado, M. (eds.). Rescate. Del registro estratigráfico a la sociedad del conocimiento: el patrimonio arqueológico como agente de desarrollo sostenible. UCO Press. Córdoba: 53-75.

Vaquerizo, D., Ruíz, A. B., Delgado, M. (eds.) (2016). Rescate. Del registro estratigráfico a la sociedad del conocimiento: el patrimonio arqueológico como agente de desarrollo sostenible. UCO Press. Córdoba.

VAquerizo GiL, D. (2015). Arqueología para un futuro incierto... La profesión de arqueólogo tras la crisis devastadora del "pelotazo". Pyrennae, 46.2: 89-120.

Vaquerizo GiL, D. (2016). Arqueología somos todos, o el triunfo de Sísifo. En: Vaquerizo, D., Ruíz, A. B., Delgado, M. (eds.). Rescate. Del registro estratigráfico a la sociedad del conocimiento: el patrimonio arqueológico como agente de desarrollo sostenible. UCO Press. Córdoba: 155-187.

Vigil-Escalera, A. (2011). El pequeño mundo en ruinas de la arqueología contractual española. Revista Arkeogazte, 1: 17-20. 
La investigación arqueológica en el marco universitario: modelos versus realidad

\author{
Sonia Gutiérrez Lloret \\ Francisco J. Jover Maestre \\ Alberto J. Lorrio Alvarado
}

\section{El contexto y los modelos}

La universidad española está en crisis, y no es que esté en crisis por el proceso de adaptación hacia un nuevo modelo que tiene como marco de referencia el Espacio Europeo de Educación Superior - a partir de ahora EEES- Está en crisis, desde nuestra perspectiva, porque se encuentra en una encrucijada de difícil resolución. La universidad tiene encomendada una doble misión: una labor formativa cada vez más compleja y exigente, en paralelo a la tarea específica de investigar y generar nuevos conocimientos que mejoren la sociedad. Pero en un mundo cada vez más competitivo, en un país que infrafinancia la investigación y con enormes dificultades para conseguirla en Europa — donde a menudo nuestra investigación arqueológica se considera "local"-, seguir ejerciendo esta labor a tiempo parcial, al 50\% del tiempo o menos, no resulta una actividad regida por los principios de eficacia y racionalidad. Ni tampoco parece ser lo más adecuado si tenemos en cuenta que en los países anglosajones la separación entre docentes e investigadores, más que una tendencia es una realidad desde hace muchos años; una realidad que, ayudada por una injustificada exclusividad lingüística, les está reportando importantes éxitos y una clara preeminencia en el acceso a recursos y medios materiales para desarrollarla. Por esta razón, cuando en la sección de Debats de esta revista se nos invitaba a reflexionar sobre la proyección de la investigación y los institutos de investigación en la universidad española y sobre el modelo universitario hacia el que deberíamos dirigirnos, nos pareció obligado comenzar por plantear una primera cuestión que subyace en el contexto actual: ¿para conseguir una enseñanza de calidad y, a la vez, ser competitivos en investigación, se debe tender hacia un modelo que separe claramente entre un cuerpo o perfil de docentes no investigadores y otro de investigadores $\mathrm{o}$, por el contrario, urge racionalizar y reconducir esta tendencia?

A tenor de lo expuesto y en respuesta a esta cuestión, podría parecer que lo más eficiente y rentable sería implantar un modelo de funcionamiento en esta línea, con una nítida separación de labores -docentes por un lado e investigadoras por otro-, a pesar de las reticencias que surgen en este sentido en el nutrido grupo de investigadores-docentes universitarios, entre los que nos incluimos. En ese escenario ficticio, que como veremos a continuación no es tan "imaginario" como se pretende, cada cuerpo de profesionales — docentes e investigadores-, debidamente formados y preparados específicamente, se dedicaría con plenitud de esfuerzos — cada vez más exigentes - hacia cada uno de los objetivos trazados, buscando una sinergia de intereses hacia la mejor y más completa formación de los estudiantes que podrían elegir y dirigir su trayectoria formativa, o bien hacia un perfil docente o bien investigador.

En cierto modo esa dicotomía ya existía en el Estado español, materializándose en la dualidad de los organismos que tienen reconocida la capacidad investigadora: investigación en el CSIC (Consejo Superior de Investigaciones científicas) ${ }^{1}$ e investigación más docencia en las universidades. Un escenario mimetizado a escala y con aparente éxito en otros ámbitos territoriales, como Cataluña, donde el ICREA (Institució Catalana de Recerca i Estudis Avançats) ${ }^{2}$ acoge una escala científica específica extrauniversitaria, con plazas permanentes de profesores de investigación en el sistema de investigación catalán y una peculiaridad específica destinada precisamente a aumentar el impacto y la proyección internacional de la investigación universitaria - la convocatoria ICREA Academia desde 2007-, y el País Vasco donde el Gobierno vasco creó en 2007 el programa Ikerbasque -Fundación Vasca para la Ciencia - ${ }^{3}$ con la misma finalidad de captar de forma permanente, o por amplios periodos, a investigadores de excelencia, que se incorporan a una escala puramente investigadora, que no existe en otras comunidades autónomas. Es indudable que esa dualidad entre centros únicamente investigadores y centros investigadores a la par que docentes, con escalas profesionales que aplican -al menos en el sistema nacional de reconocimiento de sexenios CNEAI - parámetros de evaluación similares entre profesores universitarios y profesores de investigación en sus diversas escalas, a pesar de la desigual disponibilidad en dedicación y recursos existente, genera numerosas disfunciones y lastra enormemente la investigación universitaria.

1. Creado en 1939 a partir de la disuelta Junta para Ampliación de Estudios e Investigaciones Científicas (JAE) de 1907, el CSIC tiene como misión "el fomento, coordinación, desarrollo y difusión de la investigación científica y tecnológica, de carácter pluridisciplinar, con el fin de contribuir al avance del conocimiento y al desarrollo económico, social y cultural, así como a la formación de personal y al asesoramiento de entidades públicas y privadas en esta materia”, según el artículo 4 de su Estatuto. < http://www.csic.es/presentacion> (consultado 28/10/2017)

2. Fundación financiada por el gobierno catalán que nació en 2001 "com a resposta a la necessitat de noves fórmules de contractació que permetessin competir en condicions d'igualtat amb altres sistemes de recerca, orientada a la contractació exclusiva del personal científic i acadèmic més extraordinari i amb més talent." < https://www.icrea.cat/ca/qui-som> (consultado 28/10/2017).

3. <http://www.ikerbasque.net/es/sobre-nosotros> (consultado 28/10/2017). 


\section{La realidad}

En consecuencia, la realidad se impone y a nadie debe extrañar que los docentes no investigadores - $\mathrm{O}$ al menos con un perfil investigador bajo- sean ya una realidad en la universidad española, no porque quieran $-\mathrm{O}$ al menos eso cabe pensar en muchos casos-, sino por ausencia de las condiciones adecuadas para emprender dicha actividad. Tampoco resulta sorprendente decir que buena parte de los que siguen investigando en el medio universitario, lo hacen a costa de innumerables sobreesfuerzos y sacrificios, con muy limitadas condiciones materiales y de financiación, donde la amistad y el voluntarismo siguen jugando un papel destacado, al menos en lo que a la praxis arqueológica se refiere. Esta situación, vigente desde hace más de una década, es el resultado de varios factores entre los que merecen destacarse las condiciones históricas bajo las que se ha ido configurando el mapa de universidades y de titulaciones; las consecuencias y exigencias a coste cero de la integración en el EEES; y, evidentemente, las consecuencias de la situación coyuntural de la última década, con sus reformas.

La universidad como institución social ha cumplido históricamente un papel esencial en la transmisión del conocimiento, en la formación de nuevas generaciones en diferentes ramas del conocimiento y, cómo no, en la investigación y consecuentemente en la generación de nuevos conocimientos. Las universidades -aunque existen variaciones según época y lugar- han organizado sus estudios en distintos niveles o escalas, básicamente mediante facultades, escuelas, colegios, departamentos o áreas de conocimiento, pero también a través de centros de investigación donde la concatenación entre docencia e investigación ha sido siempre la clave del edificio. Con el nuevo ordenamiento jurídico del Estado español se fue gestando un creciente optimismo social, en ocasiones casi desmesurado, que sirvió para proyectar como objetivo la consecución de la denominada "sociedad del bienestar". La puesta en marcha de este proyecto político en la década de 1980 tuvo dos pilares esenciales: democratizar y universalizar la salud pública, por un lado, y la educación y la cultura, por otro. Así, en ambas esferas no tardaron en materializarse los esfuerzos, y en el caso concreto de la educación superior, el resultado fue obvio: la multiplicación del número de universidades y/o facultades y estudios. La universidad, que había estado restringida prioritariamente a las élites, debía dar cobertura a toda la población y acercarse a los ciudadanos. La división administrativa y territorial en provincias fijadas en $1833-\mathrm{y}$ no en comunidades autónomas a las que se haría transferencia de las competencias en educación-, fue la cartografía esencial sobre la que se sustentó la implantación de nuevas universidades, sin valorar realmente la viabilidad y sostenibilidad del proyecto a largo plazo. El reparto de las competencias a las comunidades autónomas tampoco favoreció el desarrollo de un mapa común de titulaciones racional y sensato desde una perspectiva estatal en atención a diversos factores de importancia - recursos materiales, económicos, población, etc.-, sino que, más bien al contrario, favoreció la duplicidad de centros y titulaciones en territorios muy próximos. Más que "universidad para el pueblo" se trataba de "universidades para todas las provincias", sin tener en cuenta los costes y que la universidad también es un centro de investigación que requiere de una financiación específica. De este modo, se crearon en España casi tantas universidades como provincias e incluso en algunos casos - como si de proyectos presidencialistas se tratara- más de una. Al tiempo, en algunas universidades se creaban centros o institutos de investigación con la intención de potenciar específicamente algunas líneas preferentes de investigación, aprovechando la masa crítica existente o la capacidad de liderazgo de algún grupo de investigación. No fue este inicialmente el caso de la arqueología.

En este contexto de progreso social y cultural se forjó el perfil vigente de profesorado universitario, cuya dedicación se repartía por igual —en teoríaentre labores docentes e investigadoras, incluyendo la gestión docente, la representación institucional y la gestión de la investigación a través de proyectos públicos y privados. Auténticos "malabaristas", que en aquellos momentos todavía no estaban continuamente evaluados, ni a nivel docente ni investigador, como sí ocurre en la actualidad desde la implantación del EEES y del 'decreto Wert'. Este último factor ha contribuido a agrandar aún más la brecha entre investigadores y docentes universitarios, al convertir los criterios de valoración de productividad investigadora - los sexenios, hasta entonces complementos económicos y de reconocimiento académico- que se aplican por igual y sin distinción, a profesores universitarios con docencia y gestión de la docencia y a profesores de Investigación del CSIC o las fundaciones autonómicas para la Ciencia, en instrumentos de control de productividad, transformando la "docencia" en un castigo. En otras palabras, a menos investigación, medida en sexenios obtenidos, un profesor universitario debe asumir mayor carga docente - que le aboca a un círculo vicioso en el que cada vez puede investigar menos-; mientras que los profesores de investigación, captados o consolidados por su talento o capacidad dinamizadora pero igualmente permanentes en sus condiciones laborales, no son penalizados si no cumplen con los requisitos de productividad investigadora - los mismos, pese a tener un $100 \%$ de capacidad investigadora - y no obtienen un sexenio en plazo y forma. La realidad conduce ineludiblemente a un modelo de "universidad laboral" con docentes que forman para el empleo, mientras la investigación se desliza subrepticiamente a ambientes donde la docencia es testimonial. Y este camino que separa innovación y pensamiento crítico de enseñanza universitaria no es en absoluto inocente.

Por otro lado, la integración de España en la Unión Europea obligó a asumir un nuevo modelo a partir de la década de 1990, cuyas directrices en materia de educación superior se fueron configurando en diversas convenciones y acuerdos establecidos en distintas ciudades europeas. Se aprobaba así la inclusión de la universidad española en el EEES, no solo para normalizar un marco mínimo y común para la obtención de titulaciones de reconocimiento europeo, 


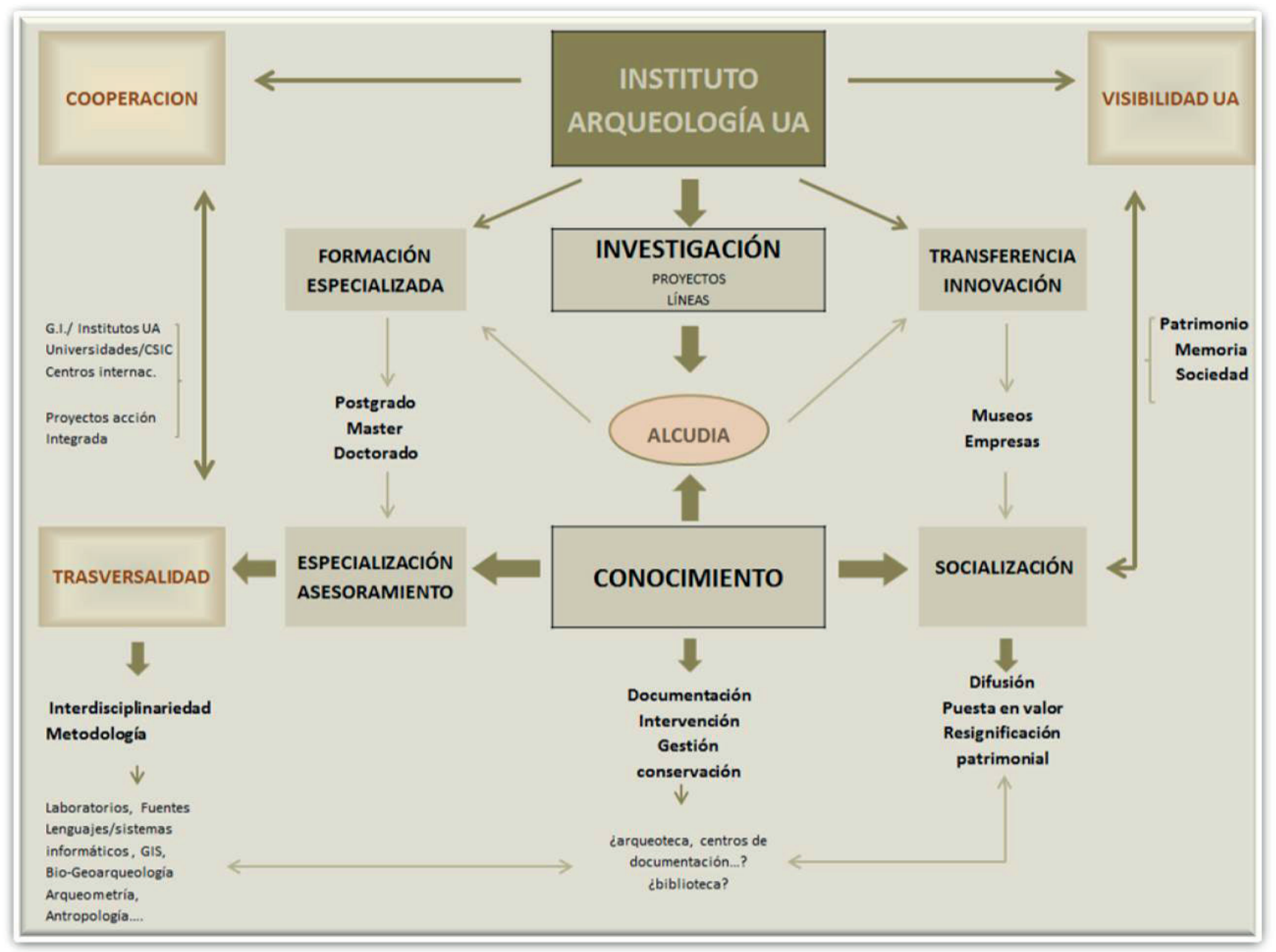

Figura 1. Esquema conceptual sobre los campos de acción del Instituto Universitario de Investigación en Arqueología y Patrimonio Histórico de la Universidad de Alicante - INAPH.

sino también de progresiva mejora de la calidad de la enseñanza y de las ofertas formativas, verificado y acreditado a través de sistemas de control y de procesos periódicos de evaluación. La continuidad y la sostenibilidad de planes de estudios y de universidades dejaron de estar garantizadas a priori, en un nuevo marco en el que los discentes comenzaron a considerarse "clientes" en lugar de estudiantes y los docentes formadores para el empleo antes que transmisores de conocimiento y pensamiento crítico. Desde esta nueva perspectiva, solo serían viables aquellas universidades competitivas con relación al cumplimiento de una serie de parámetros establecidos desde el ámbito empresarial —desarrollo de proyectos de interés empresarial, liderazgo, emprendimiento, captación de financiación, visibilidad social, etc.Esta situación no ha hecho más que acrecentar la competitividad entre universidades en detrimento de la competencia, con el objetivo básico de conseguir su sostenibilidad en unos casos y, en otros, de buscar la denominada excelencia al objeto de obtener mayores fuentes de financiación. En esta coyuntura de creación de una política científica nacional propia se enmarca la creación del ICREA en 2001, con la finalidad de contratar a un destacado cuerpo de investigadores de talento y vincularlos a los centros de investigación y universidades catalanas, lograr un mejor posicionamiento en los rankings de evaluación y conseguir mejores y mayores dotaciones. Es innegable que la política desarrollada en este sentido por la Generalitat de Catalunya ha sido muy exitosa en resultados de investigación y fondos obtenidos, igual que la vasca, con respecto al resto del territorio español, si bien conviene también recordar que en ambos casos han duplicado las posibilidades de financiación pública de la investigación, constreñida en el resto del Estado español exclusivamente al Plan Nacional de $\mathrm{I}+\mathrm{D}+\mathrm{i}$ y a las cada vez más evanescentes o directamente inexistentes convocatorias autonómicas durante la última década.

Frente a ello, otra de las medidas adoptadas por las universidades ha sido la creación de institutos universitarios de investigación — también en la arqueología, aunque en menor número-, como forma de concentrar, coordinar esfuerzos y aunar sinergias de investigadores y grupos de investigación en pocas líneas de investigación, socialmente necesarias, que puedan ser competitivas. De este modo, en las últimas décadas han sido creados en distintas universidades, y no por casualidad de forma prioritaria en Cataluña, algunos institutos de investigación en materia arqueológica - CEPAP en la UAB; ICAC e IPHES en la Universidad Rovira i Virgili; Instituto Internacional de Investigaciones Prehistóricas de Cantabria; Centro Andaluz de Arqueología Ibérica en la Universidad de Jaén, entre otros- En concreto, un reducido número 


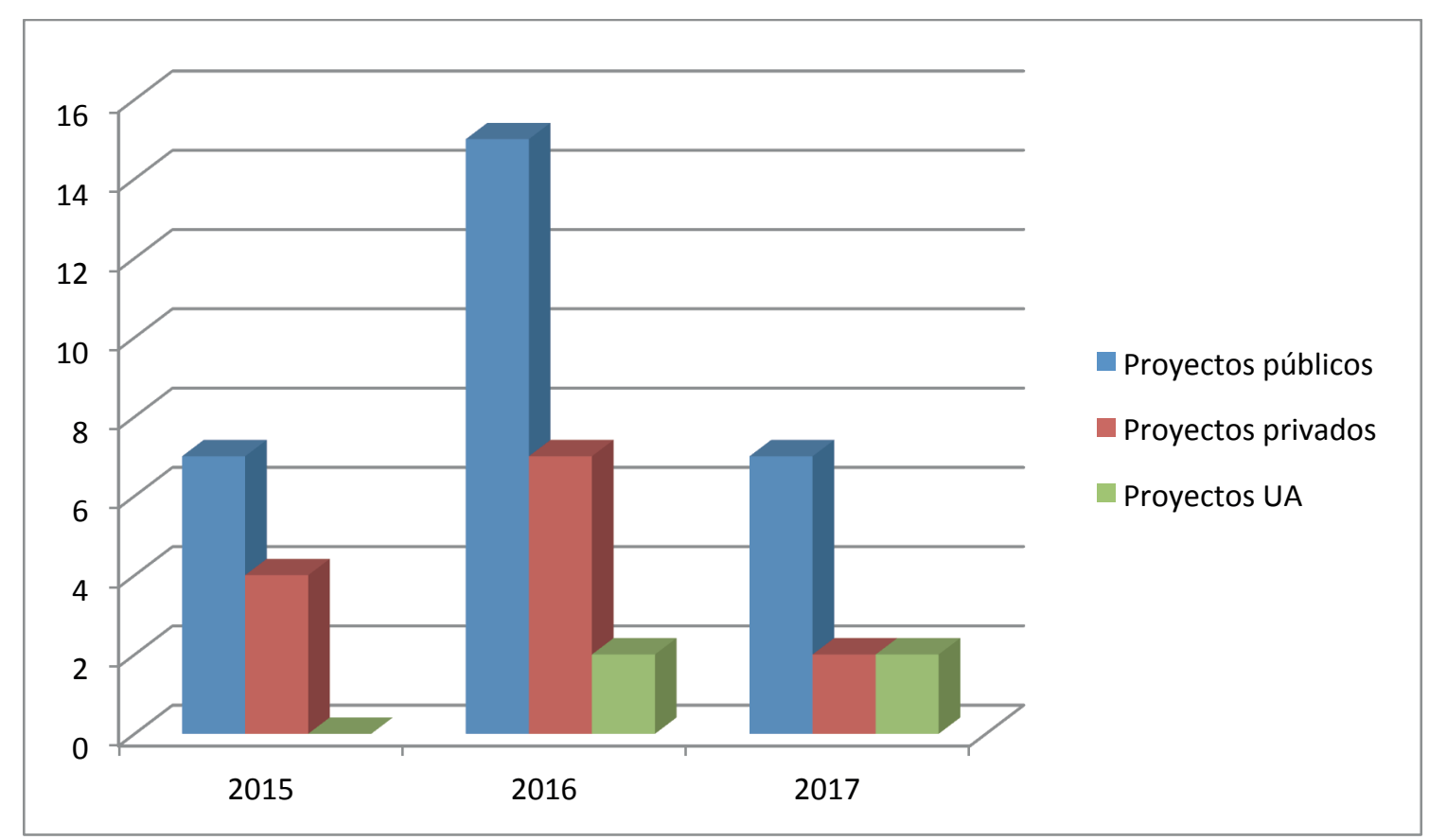

Figura 2. Número —en valores absolutos- y tipología de proyectos gestionados en el INAPH desde su creación.

de institutos con unas líneas de investigación muy definidas, a los que desde septiembre de 2014 -Decreto 149/2014 de 19 de septiembre del Consell de la Generalitat Valenciana- debemos añadir el Instituto Universitario de Investigación en Arqueología y Patrimonio Histórico - $\mathrm{INAPH}^{4}$ - en la Universidad de Alicante (figura 1), con el fin de fomentar la investigación arqueológica del patrimonio histórico desde una perspectiva global, integrando a dos grupos de investigación consolidados - Prehistoria y Protohistoria y Arqueología y Patrimonio Histórico-, junto a especialistas de otras áreas de conocimiento como la Historia, la Arquitectura, la Antropología física, la Filología, la Biotecnología, el Derecho, la Geografía, el Turismo y la Economía.

En este último caso que nos atañe, como en la mayoría de los institutos universitarios, la creación de un instituto no supone sino un marco institucional sinérgico que no lleva aparejada una financiación científica comparable a la que se ha producido en el modelo vasco o catalán. Más allá de la financiación básica de gestión, similar a la de un departamento universitario, el instituto solo amalgama y gestiona los recursos propios de los investigadores y grupos de investigación adscritos derivados de los proyectos públicos, privados y propios (figura 2) y de las tesis dirigidas o complementos investigadores propios.

La pertenencia a un instituto universitario no supone en ningún caso un reconocimiento en descarga docente en beneficio de la investigación para sus miembros, ni tan siquiera en el caso de los cargos personales de dirección que, en el mejor de los casos, ven reducida su carga docente al 50\% de la estipulada por la universidad, que en el caso de la de Alicante nunca puede ser inferior a 11 créditos.

4. <https://inaph.ua.es/> (Consultado el 28/10/2017).
Su creación tampoco lleva aparejada una escala profesional científica y, al menos en el caso de nuestra universidad y a diferencia de otras, debe hacerse cargo de la financiación o cofinanciación de los becarios postdoctorales, contratados Juan de la Cierva o Ramón y Cajal, así como de cualquier otra figura contractual de la Ley de la Ciencia, de sus propios fondos. Es más, después de tres años de activa existencia las promesas de la universidad de dotarnos de espacios adecuados — despachos, seminarios, laboratorio, etc.todavía no se han cumplido.

Ahora bien, la implantación del EEES ha supuesto, entre otras consecuencias, un profundo cambio en los planes de estudios, con una drástica reducción del número de créditos de determinadas áreas de conocimiento -en especial en los ámbitos históricos y humanísticos a los que se suele adscribir la arqueología en el ámbito europeo no anglosajón-, sin que se haya modificado el paradigma clásico de "a mayor número de créditos, mayores posibilidades de contar con docentes-investigadores y de crear/ consolidar grupos de investigación potentes y a la inversa". Problema que adquiere tintes dramáticos cuando plantillas envejecidas han visto cercenada, en el marco de la crisis, la tasa lógica de reposición y la política de las universidades sigue siendo la de abusar de la figura del profesor asociado, evitando la consolidación de plantillas estables. En general, predomina una universidad envejecida que no puede absorber la masa crítica formada en el sistema público español y europeo que desea volver, y en consecuencia incapaz de garantizar el relevo generacional del conocimiento, ni de captar, o peor aún, estabilizar los talentos captados. Una universidad pública mal financiada, cercada por las universidades privadas crecidas al albur de lo público, y donde la investigación es a menudo un compromiso personal y un esfuerzo colosal. 
Así, muy pocas universidades españolas, aquellas que contaban con una amplia masa crítica o que tuvieron la posibilidad de desarrollar una titulación interuniversitaria, pudieron aprovechar la coyuntura para crear un grado en Arqueología; y casi en las mismas, de ofertar, además, un máster. No por casualidad, y con alguna excepción, es en estas mismas universidades donde coincide la oferta de estudios en arqueología, con la creación de institutos universitarios de investigación.

Y, por si fuera poco, la situación ha empeorado ostensiblemente desde la crisis económica iniciada en 2007-2008. Entre otras cuestiones, se ha producido un descenso evidente en el número de estudiantes de primera matrícula por el incremento de las tasas, tanto en grado como en máster; muchas facultades han tenido que afrontar reestructuraciones de estudios y uniones departamentales de graves consecuencias para el desarrollo de la investigación; han aumentado las cargas burocráticas del profesorado con la implantación de los sistemas internos de garantía de calidad, además del esfuerzo de adaptación docente a las nuevas modalidades organizativas y uso de TICS; se han precarizado las plantillas y en consecuencia se han reducido las posibilidades de obtener proyectos de investigación, cada vez peor dotados. Sin olvidar que la presión ejercida sobre los profesores universitarios para acreditar una investigación puntera no redunda necesariamente en una mejora docente y produce a menudo un daño colateral: la desmotivación investigadora y docente. A esta situación general cabe añadir, al menos desde nuestro punto de vista, otros tres elementos que han aumentado las dificultades para investigar en arqueología:

1. La práctica arqueológica es una actividad investigadora cuyos costes se han ido incrementando de forma exponencial en los últimos años. Ya no solo por lo que supone contar con amplios equipos de trabajo de prospección o de excavación, sino por la necesidad de invertir cada vez más en una amplia y variada gama de analíticas, sin las cuales los resultados obtenidos carecen de los estándares científicos que hoy se exige a una investigación puntera.

2. La necesidad de equipos interdisciplinares cada vez más numerosos y difíciles de aunar bajo unos intereses comunes, donde primen los estudios históricos, arqueológicos o patrimoniales, sobre todo, si lo que se pretende es conseguir buenos resultados de investigación histórica y difundir nuestros resultados en publicaciones de impacto.

3. La imposibilidad de consolidar equipos capaces de investigar sinérgicamente y aumentar exponencialmente los resultados investigadores y en consecuencia captar recursos.

Por lo pronto, al menos en el campo de la investigación arqueológica ya se detectan significativas diferencias entre comunidades autónomas, instituciones y resultados de investigación. La política catalana, iniciada hace ya tres lustros -y lo mismo cabría decir del caso vasco - ha situado a algunas de sus instituciones en una posición de ventaja sobre el resto de comunidades autónomas, donde no se ha producido una situación similar —ni parece que se considere un tema prioritario a corto y medio plazo-, a pesar de su evidente repercusión en aspectos tan destacados como la mejora en los rankings de evaluación o la obtención de mejores y mayores dotaciones, lo que en última instancia redunda en el mayor prestigio de las instituciones que han optado por esa vía. Por su parte, la creación de institutos universitarios de investigación en materia arqueológica ha permitido afianzar las posibilidades de investigación, y, por extensión, mantener una oferta formativa en estudios arqueológicos.

Con todo, y sin ánimo de ser pesimistas, creemos que en muchas universidades con grados en Historia o Humanidades, los contenidos en materia arqueológica se reducirán todavía más, en clara correspondencia con la reducción de las plantillas docentes. Como consecuencia, los estudiantes que quieran formarse en arqueología acabarán desplazándose a aquellos centros nacionales o internacionales con una oferta formativa atractiva, variada y con condiciones para el desarrollo de la investigación. Es posible que, en unos años, los estudios en arqueología queden reducidos a unas pocas universidades, probablemente, en aquellas que hayan apostado por una específica y amplia oferta formativa en arqueología y patrimonio y, a su vez, apuesten por la investigación, probablemente, a través de institutos desde los que canalizar líneas preferentes de investigación. Por esta razón la creación de institutos universitarios de investigación de orientación arqueológica es probablemente el vehículo que, en estos momentos, puede facilitar y posibilitar el desarrollo de las labores de investigación encomendadas a los docentes - siempre que así se pretenda- e, impedir la reducción e incluso, la desaparición de los estudios y las investigaciones en arqueología en muchas universidades españolas.

\section{¿El futuro?}

Ahora solo falta conocer si nuestras autoridades están pensando en apostar por un modelo donde se materialice la separación oficial entre docentes universitarios no investigadores —con las nefastas consecuencias que se prevén para la formación y el sentido de las universidades- e investigadores a tiempo completo; o simplemente se apueste por incorporar a las universidades un cuerpo específico de investigadores a tiempo completo, siguiendo el modelo ICREA en Cataluña. Quizá quepa pensar en un modelo flexible que, manteniendo la docencia como vehículo de inserción en la realidad social y sin renunciar al carácter de vanguardia que han de tener los centros de enseñanza superior, prevea y facilite la permeabilidad entre ambos universos - docente e investigador-, no "castigando" con docencia a quien no investiga, sino premiando al docente investigador, es decir, facilitándole el tiempo y los recursos necesarios para liderar equipos y proyectos punteros en el marco de institutos de investigación universitarios, que significa "investigar en y para la universidad" y no al margen de ella. Por el momento y desde hace años, el inmovilismo parece ser la mejor solución para quienes nos dirigen, mientras se corre el ries- 
go - por desgracia cada día más próximo- de que la investigación universitaria sea pronto un recuerdo comparable al Trivium et Quadrivium.

Sonia Gutiérrez Lloret Francisco J. Jover Maestre Alberto J. Lorrio Alvarado Instituto Universitario de Investigación en Arqueología y Patrimonio Histórico (INAPH) - Departamento de Prehistoria, Arqueología, Historia Antigua, Filología Griega y Filología Latina. Universidad de Alicante. Carretera de San Vicente del Raspeig, s/n, 03690 San Vicente del Raspeig inaph@ua.es

\section{L'arqueologia} com a exemple de la progressiva deslocalització de la recerca o la (buscada) mort del professorat universitari

\section{Josep M. Fullola Pericot}

El debat que se'ns planteja no pot ser més candent ni més actual i incideix directament en el model de recerca, essencialment aplicada a l'arqueologia, que volem per al país.

Tampoc no hem d'amagar que les persones que participem en el debat venim condicionades pel nostre lloc de treball, per la dinàmica en la qual ens hem vist immersos en les darreres dècades, intentant fer avançar la recerca (arqueològica) des de la nostra institució.

A casa nostra hi havia hagut instituts dedicats a la recerca arqueològica des de principis dels anys seixanta, i en institucions força diferents. Recordem només l'Institut d'Arqueologia i Prehistòria de la Universitat de Barcelona, fundat per Joan Maluquer de Motes i Lluís Pericot el 1959 i que es declarà continuador de l'escola arqueològica barcelonina; i l'Institut de Prehistòria i Arqueologia de la Diputació de Barcelona, amb seu al Museu d'Arqueologia de Barcelona, fundat per Eduard Ripoll també el 1959, i que es declarà, per la seva banda, continuador de la tasca del Servei d'Investigacions Arqueològiques d'abans de la guerra. Altres instituts havien dedicat part dels seus esforços al tema arqueològic, com l'IEI o l'Institut d'Estudis Gironins, entre d'altres de caràcter més local.

Però aquest model va anar desapareixent al llarg dels vuitanta, o va quedar constrenyit a vestigis residuals pel que fa a la recerca arqueològica.
L'arribada de la Generalitat, amb competències en arqueologia des del 1981, no va suposar cap canvi en les estructures de recerca arqueològica. Es donaven permisos d'excavació (que no programes) a diverses institucions com universitats, museus $\mathrm{i}$ serveis municipals o provincials. La llavors existent Direcció General de Recerca mai no va convocar programes específics d'arqueologia durant les dues dècades finals del segle xx. Hem d'esperar-nos fins al 2006, amb l'efímer programa EXCAVA, per trobar una programació concreta del nostre camp. Des del Servei d'Arqueologia es comença a posar una mica d'ordenació a mitjà termini des del 1995, quan apareixen les programacions triennals (1995-1997), quadriennals (1998-2001 o 2014-2017) o sexennals (2002-2007 i 2008-2013).

La creació d'un comissariat d'Universitats i Recerca el 2001 va fer concebre certes esperances, en veure juntes, en el títol de l'organisme, les dues realitats que sempre havien anat de la mà, de manera prou profitosa. L'aparició del fenomen ICREA, que volia insuflar força addicional als grups de recerca, fou molt positiva per a les universitats amb grups de recerca potents.

Però, de manera paral-lela, Mas Colell es va treure de la màniga la figura dels instituts de recerca i, en certa manera, la contraposà als grups d'investigadors universitaris. Cert és que la majoria dels nous instituts de la Generalitat estan vinculats a alguna universitat, però el seu funcionament intern és totalment autònom, amb finançament procedent de la mateixa Generalitat i d'institucions locals, comarcals o provincials.

Hom no dubta de les bones intencions de centralitzar la recerca arqueològica del país en dos instituts (el Consorci ICAC i la Fundació I[C]PHES), als quals després s'afegirien l'ICP i l'ICRPC, centrats aquests dos darrers bàsicament en temes de paleontologia $\mathrm{i}$ patrimoni respectivament. Tanmateix el cert és que l'ascens dels instituts concideix, dramàticament, amb el menysteniment que les universitats patim, en recursos $\mathrm{i}$ en places, des de mitjan la primera dècada del segle xxI, i la balança s'ha inclinat, i segueix inclinant-se, de la banda dels primers.

No és objectiu d'aquestes línies criticar una cosa per potenciar-ne una altra. La trajectòria dels instituts esmentats és ben diferent, des dels que estan dedicats amb preferència a les publicacions d'articles d'impacte fins als que tenen col-leccions pròpies de llibres, passant pels que van fent el que els permeten les circumstàncies. Per si mateix, el balanç no el podem considerar negatiu.

Però on sorgeix el greuge comparatiu és quan considerem el que havia estat sempre la punta de la recerca, el professorat universitari que en feia i, al mateix temps, enriquia la seva docència amb l'experiència investigadora, amb excavacions, treballs de laboratori, analítiques, tesis doctorals que tenien la conseqüència de la formació reglada i paral.lela de joves arqueòlegs, de persones que podien agafar un relleu generacional natural.

I és en el camp universitari on la Generalitat està fent una política activa que no afavoreix gens ni mica la recerca, permeteu-me aquesta frase tan rotunda. Els esforços per atreure talent investigador extern 
en places de professor (Serra Hunter, tenure track...) han fracassat estrepitosament, ja que pràcticament sempre acaben guanyant aquestes places gent de casa, que volen seguir cobrant les quantitats minses i desfassades que cobrem, que mai no podran ser un estímul suficient per fer venir aquí talent extern, ben col-locat a països amb molt més interès pel binomi docència/recerca que ha de fer un professor universitari. Només les injeccions externes com ICREA o el programa Ramón y Cajal han aportat talent investigador, però no docent.

Però no s'atura aquí la degradació del professorat universitari. Les jubilacions de catedràtics i de titulars, persones que exercien, en la majoria de casos, de pals de paller per a molts grups de recerca consolidats, no s'han vist compensades amb noves places d'aquestes categories, estructurals i bàsiques per donar una continuiltat als equips que han estat funcionant amb empenta des de mitjan els noranta. La seva substitució per professors associats, precaris, renovats any a any i que no tenien dedicació efectiva a la recerca, ha anat matant aquests equips, els ha anat fent desaparèixer per manca d'efectius i de resultats; la majoria de les convocatòries no permeten integrar associats de contractació anual, i això els impedeix constar com a investigadors.

També és degradació del professorat universitari impedir la lliure elecció de la via que vol escollir el professor que ha acabat el seu període de formació, amb totes les acreditacions hagudes i per haver (lector, agregat, contratado doctor, titular...). La sibil.lina pressió (deixeu-m'ho dir en termes florentins, i qui potest capere, capiat) de la Direcció General d'Universitats sobre les universitats del país ha fet, en aquests darrers anys, que la precarització augmenti encara més, si cap. Ha aparegut la demencial figura dels agregats interins i, sobretot, s'ha impedit la convocatòria de places de titulars i de catedràtics que substituïssin els pals de paller caiguts per jubilacions, decessos $\mathrm{i}$ abandonaments prematurs. La recerca, l'arqueològica i la que no ho és, s'ha degradat a la universitat per manca de relleu generacional.

Podem encara afegir-hi la miop comptabilització que fa la DGU de les hores de dedicació d'un professor universitari. Es penalitza la rebaixa docent per l'excel-lència en recerca, es busca carregar i comptabilitzar el màxim d'hores docents sobre el professorat i menystenir el vessant investigador. Tot fa pensar que es vol arribar a la figura del professor-no-investigador, del lloro de repetició dels coneixements ja establerts, que podran acabar sent difosos a través de gravacions. Si un professor no fa recerca, no innova, no excava ni publica, en el nostre cas dels arqueòlegs, no aporta res de res a la societat que el paga.

Seran els instituts el futur únic de la recerca? No, de cap manera, ja que això suposaria, com es pot deduir dels paràgrafs anteriors, la mort de la universitat en extirpar-li la meitat de la seva totalitat indissoluble, la recerca. Però, si veiem la convocatòria dels SGR 2014, només un terç del finançament va anar a grups universitaris, i més de la meitat a instituts (sota la denominació de Centres CERCA). Si la distribució dels SGR 2017, en curs d'avaluació en el moment de redactar aquestes línies, marqués unes xifres encara més distants, menors per a les universitats i majors per als instituts, la deriva suïcida del desequilibri buscat, de l'anihilació de les estructures universitàries de recerca, prendria cos en aquest país, i es faria estructural.

Larqueologia no seria més que un dels camps científics afectats negativament per aquesta deriva. Els plans pluriennals del Servei d'Arqueologia i Paleontologia, en el cas de seguir existint, aniran caient gradualment de la part dels instituts, per manca de grups potents universitaris que estructurin la seva recerca arqueològica al voltant d'excavacions programades, amb una justificació científica al darrere i amb una visió docent, de formació. Els dos graus d'arqueologia que tenim a Catalunya no podran oferir una veritable sortida professional de recerca, i el refugi dels instituts seguirà sent una possibilitat molt menys abastable que les universitats, sense una manera d'entrar-hi clara, sense unes places que surtin a concurs públic, sense una estructura interna comuna (un és un consorci, un altre és una fundació, un altre és un institut...). No és el futur que vull per al meu país, però suposo que aquest dossier del RAP plantejarà alternatives molt diferents a la que jo percebo. Només ens cal desitjar que els que detinguin el poder polític escoltin els investigadors, escoltin els docents universitaris i reconsiderin unes postures extremes que ens porten, en el cas concret de l'arqueologia, cap a una concentració de la recerca francament negativa.

Josep M. Fullola Pericot Catedràtic de Prehistòria i director del SERP Secció de Prehistòria i Arqueologia, Departament d'Història i Arqueologia, Facultat de Geografia i Història Universitat de Barcelona

Carrer de Montalegre, 6, 08001 Barcelona fullola@ub.edu

\section{Molta fressa i poca endreça. La recerca} en arqueologia a Catalunya. Instituts de recerca i universitats. Cap a un nou model
universitari?

\section{J. M. Nolla i Brufau}

Em sembla que no es pot respondre aquesta pregunta d'una manera simple, sense matisos: hi ha al darrere, també (o em dona aquesta sensació), 
una valoració global de la situació, ara mateix, de la recerca arqueològica a casa nostra, on som i on volem anar.

Quan es dissenyà i s'aprovà allò que per simplificar podem anomenar pla Mas Collell, les humanitats, les lletres, no hi eren convidades. La festa era per a uns altres. I si finalment l'arqueologia prehistòrica i l'arqueologia clàssica van ser afavorides amb la creació de dos d'aquells nous instituts que havien de liderar la recerca d'alt nivell, allò no canviava, no ens enganyem, l'esperit de la llei. Era la torna i menys per l'IPHES que juga a un altre nivell en tractar qüestions que són més pròximes de les ciències experimentals, que per l'ICAC. I no ens fem il.lusions, aquí som i aquí romandrem. Aquest és, segons la nostra opinió, el nostre (principal) problema. No som. No interessem especialment; signifiquem ben poc en la idea de l'alta recerca. I no ens fem il.lusions, les coses no canviaran ni a curt ni a mitjà termini. Si de cas, empitjoraran. No es veu en l'horitzó polític una voluntat de redefinir la situació, de dissenyar unes noves regles de joc. I, podríem dir, comparant-nos a molts altres estudis del món de les humanitats, que encara tenim sort, que se'ns ha tingut en compte.

Si ara, després d'aquestes consideracions inicials que m'ha semblat oportú escriure, ens centrem en el tema plantejat, si la recerca basada en grans instituts de recerca pot acabar afectant globalment les altres institucions que, fins ara, s'hi dedicaven, jo seria optimista pel que fa a l'arqueologia.

No veig cap raó, cap indici, que em faci pensar que l'ICAC pugui acabar esdevenint l'única institució ben dotada i, per tant, l'única que pugui endegar i executar (grans) projectes de recerca. Per arribar fins a aquest punt, caldria un canvi que no em sembla possible i sobre el qual no hi ha cap senyal ni fort ni feble. És, ara, un grup més que participa, com els altres, en el repartiment. I no tenen ni tindran (si no hi ha un canvi tan radical que ens agafi a tots per sorpresa, ben improbable) possibilitats de créixer més enllà d'on són. I no n'hi haurà cap altre.

Ens haurien de preocupar molt més altres qüestions que sí que podrien significar un empobriment, un retrocés en relació amb la situació actual que, diguem-ho ben alt, no és òptima i que podria i hauria de ser millor però que si la comparem amb la de fa una generació no deixa de sorprendre el salt quantitatiu i qualitatiu que ha fet.

El problema més imminent és aguantar les posicions davant el desballestament d'allò que s'havia anat bastint amb dificultats i amb constància. No hi ha, a la universitat, reposició de places si no és de manera extraordinària. La burocràcia a tot nivell s'ha fet tan poderosa i tan absurda que ho ofega tot. Soc de l'opinió que convindria seguir un camí propi, diferent del de les ciències experimentals que sovint apliquem de manera automàtica forçant la situació per adaptar-nos malament a uns paràmetres on tot grinyola. Arribar on som ha estat difícil, feixuc, una llarga tasca plena de destorbs i noses. Cal aguantar el que tenim, hem de mantenir-ho. I no només no serà fàcil, sinó que caldrà suar tinta per no perdre pistonada.
Els problemes, pel que fa al nostre camp de recerca, no vindran d'aquesta nova orientació (grans instituts).

J. M. Nolla i Brufau Catedràtic d'Arqueologia

Laboratori d'Arqueologia i Prehistòria (Institut de Recerca Històrica), Universitat de Girona, Pl. Ferrater Mora, 117071

Girona

josep.nolla@udg.edu

\section{Investigar a}

\section{Catalunya a inicis del segle XXI: instituts de recerca o universitats?}

\section{Maria Carme Belarte}

La petició de la Revista d'Arqueologia de Ponent del meu punt de vista sobre el binomi instituts de recerca i universitats i l'actual model universitari a Catalunya m'ha portat a reflexionar sobre les polítiques de recerca del darrer quart de segle i sobre allò que, al meu entendre, són els factors que han conduït a la situació actual, i que inclouen tant l'administració com el comportament de les pròpies institucions de recerca implicades. Així mateix, he mirat de plantejar algunes perspectives de futur. Seguidament trobareu el meu intent de plasmar aquestes reflexions per escrit de la manera més clara i objectiva possible, si bé inevitablement està basat en part en experiències tant personals com d'altres casos propers.

La investigació actual a Catalunya es fonamenta sobre bases derivades de l'orientació que, de la mà de la figura del conseller Mas Colell, va adoptar la política de recerca de la Generalitat de Catalunya des de l'any 2001. A partir d'aquest moment, es varen produir importants canvis que afectarien tant a persones com a institucions vinculades a la investigació, i que es resumeixen fonamentalment en dos: la creació dels instituts de recerca i l'aparició de noves figures de personal investigador. Al seu torn, ambdós han incidit en la distribució de recursos i de personal investigador entre els centres de recerca; en el cas del segon factor, a més, els canvis endegats des de Catalunya es van afegir a d'altres impulsats per part del govern central, i van implicar, com es veurà, una disminució general del nombre d'investigadors/ res contractats. Però per analitzar alguns aspectes de la situació actual de la investigació cal remuntar algunes dècades en el temps, abans que s'iniciessin els canvis a què hem al.ludit.

Durant la dècada dels noranta, la tasca investigadora es desenvolupava de manera pràcticament exclusiva en el si de les universitats. Tot i amb això, aquestes no havien aconseguit crear un cos de personal investigador dedicat exclusivament (o fona- 
mentalment) a aquesta activitat. Per norma general, no es va apostar fermament per crear una figura que permetés consolidar aquelles persones que, durant anys, i gràcies a un seguit de beques i contractes més o menys precaris, havien anat reforçant els equips de recerca. La carrera investigadora aleshores solia passar per tres estadis: les beques predoctorals - que no van esdevenir contractes fins anys més tard-, les beques d'estada a l'estranger i, finalment, un o més contractes de reincorporació de doctors. Alguns vicerectors de recerca havien anunciat en diverses ocasions la creació de contractes estables per als investigadors postdoctorals que havien passat per totes les etapes esmentades (finalitzades les quals no existia cap altra opció fora de la via del professorat universitari — tampoc fàcil, com és ben sabut-), però malauradament aquesta situació mai va arribar a ser una realitat. Si bé les limitacions econòmiques van ser sens dubte un factor important per fer-se enrere a l'hora d'endegar aquestes contractacions, també és cert que els investigadors postdoctorals (i també els predoctorals) s'anaven substituint per aquells seleccionats en les convocatòries subsegüents, de manera que el nombre d'investigadors i investigadors en formació a les universitats era sempre més o menys constant sense necessitat d'inversió econòmica en personal.

Amb el canvi de segle es van produir diverses situacions en què des de les universitats es varen deixar passar el que després resultarien haver estat les darreres oportunitats —almenys fins al moment actual - per crear aquesta figura. Per una banda, el 2001 va tenir lloc l'extinció dels anomenats contractes de reincorporació de doctors que convocava el govern central (a través dels successius ministeris amb competències de recerca, equivalents en les seves funcions a l'actual Ministeri d'Economia i Competitivitat, i que han anat canviant de nom) i la seva suposada reconversió en els investigadors del programa Ramón y Cajal (d'ara endavant, RyC). Fins aleshores, per a tots aquells doctors que havien aconseguit fer una estada postdoctoral de dos anys a l'estranger era relativament fàcil (gairebé automàtic) aconseguir un contracte de reincorporació de fins a tres anys sempre que hi hagués al darrere un projecte $d^{\prime} \mathrm{R}+\mathrm{D}$ vigent finançat pel mateix ministeri. Els contractes de reincorporació de doctors de la Generalitat de fins a dos anys de durada, de característiques similars als del ministeri, permetien als investigadors sumar en total un màxim de cinc anys de contractació postdoctoral si gaudien dels dos programes successivament. Ara bé, l'aleshores nova convocatòria $\mathrm{RyC}$ va suposar una important reducció del nombre d'investigadors contractats, amb la necessària exclusió (i, amb el temps, extinció) de nombrosos investigadors postdoctorals que gaudien d'un contracte vigent a través dels anteriors programes.

Per una altra banda, es va produir la desaparició, gairebé en paral.lel, de les convocatòries de reincorporació de doctors de la Generalitat, coincidint amb l'inici del programa ICREA. Però, un cop més, el programa ICREA no absorbiria el nombre d'investigadors perfectament preparats que havien passat per tots els estadis del sistema anterior. A més, si els contractes de reincorporació anteriors demanaven com a requisit haver fet estades a l'estranger de dos anys, ICREA n'exigia un mínim de quatre, de manera que encara limitava més el nombre de possibles candidats. L'aparició del programa ICREA Junior el 2005 rebaixava els requisits per optar a un contracte d'investigador, encara que amb durada determinada, però va ser suprimit al cap de tan sols cinc anys.

Davant d'aquesta situació, que va implicar una dràstica reducció dels contractes postdoctorals, en algunes universitats es va anunciar la intenció de buscar solucions puntuals per tal que els antics reincorporats que no havien pogut entrar en els nous programes poguessin continuar la seva recerca vinculada a les universitats. No obstant això, la resposta no es va materialitzar en la major part de casos, i només puntualment es van arribar a trobar solucions per mirar d'evitar la pèrdua de massa crítica investigadora, amb la creació de contractes propis que vinguessin a afegir-se a aquells que s'obtenien a través de les convocatòries competitives esmentades.

El canvi en les perspectives d'estabilitat i de possibilitats de dedicar-se a la recerca per als investigadors postdoctorals, però, no consistia només en la reducció del nombre de contractes sinó que, en el cas de la convocatòria RyC, també va comportar, a curt termini, un canvi en el propi perfil dels investigadors sèniors resultants. En efecte, aquest programa implicava el compromís, per part dels centres receptors, d'estabilitzar l'investigador contractat mitjançant la creació d'una plaça un cop passats els cinc anys que preveia el programa. Però la solució adoptada per les universitats no ha estat la creació de places d'investigador pròpiament dites, sinó de professor agregat en el marc del programa Serra Hunter. Així, els investigadors $\mathrm{RyC}$ adscrits a les universitats s'han acabat reconvertint en docents, amb la conseqüent disminució del temps que poden invertir en recerca. El mateix ha passat amb les escasses persones que gaudien encara de contractes temporals de recerca a les universitats i a qui s'ha arribat a estabilitzar. En canvi, aquells que desenvolupen el seu període com a investigador RyC en un institut de recerca acaben normalment ocupant una plaça d'investigador sènior convocada per la institució.

A tot el que s'ha dit cal afegir un altre factor: el fet d'oferir una plaça dins la convocatòria RyC implica, per al centre receptor, un esforç econòmic important. Això ha provocat que la majoria d'universitats ofereixin poques places en el marc d'aquesta convocatòria $i$, en conseqüència, ha empès els candidats escollits a adscriure's a instituts de recerca que, en general, accepten més sol-licituds. El mateix passa amb altres tipus de contractes postdoctorals, de modalitat júnior (el més representatiu dels quals seria el programa Juan de la Cierva) per als quals també s'ofereixen més places des dels instituts que des de les universitats.

Pel que fa a la figura dels investigadors contractats a través d'ICREA (anomenats professors d'investigació), actualment constitueixen, a la major part d'universitats, l'únic cos de personal dedicat exclusivament a la recerca, amb una càrrega docent absent o molt minsa, d'acord amb l'investigador i amb una remuneració complementària per part de la universitat. Aquesta 
figura d'investigador amb dedicació gairebé exclusiva avui suposa gairebé una anomalia a la universitat, i en alguns departaments universitaris l'encaix dels professors ICREA no sempre ha estat fàcil.

A tot això s'afegeix, en els darrers anys, la reducció de contractació de professorat universitari i la dràstica disminució del nombre de places de funcionari que es convoquen (darrerament, moltes jubilacions i defuncions de professors titulars i catedràtics s'estan cobrint a base de contractes de professor associat), la qual cosa no només comporta una precarització del professorat sinó també la sobrecàrrega docent i la disminució del temps que aquest pot dedicar a investigar. A més, en el cas dels professors associats, la tasca investigadora no és ni reconeguda ni remunerada, i fins i tot queden exclosos com a investigadors en algunes convocatòries.

En aquest context, la creació dels instituts de recerca per la Generalitat d'ençà del 2001 es presenta com una oportunitat per contractar investigadors, mitjançant convocatòries pròpies, que poden dedicar-se plenament (o gairebé) a la recerca, amb una participació en les tasques docents que, depenent del centre i del tipus de vinculació amb la universitat a què estiguin adscrits, pot produir-se a diferents nivells, però que normalment és molt reduïda.

Tenint en compte els factors esmentats, sembla lògic que els investigadors que opten a consolidar-se a través de les convocatòries tant catalanes com espanyoles (però també a través de convocatòries europees), triïn els instituts de recerca com les institucions d'acollida per davant de les universitats, ja que és la manera com hi ha més possibilitats que en un futur es puguin dedicar exclusivament (o prioritàriament) a l'activitat investigadora i amb un millor encaix amb el centre.

A la preferència pels instituts no és aliè el fet que, almenys en els primers anys des de la seva creació i fins a l'arribada de la crisi que ens afecta des del 2009, aquests han gaudit per norma general de situacions pressupostàries avantatjoses i millors installacions i equipaments, que resulten més atractius per captar els investigadors que puguin arribar a través de convocatòries per via competitiva. Cal dir, però, que a partir del 2009 els instituts de recerca també han reduït la contractació d'investigadors a través de convocatòries pròpies i que fonamentalment acullen personal que ha obtingut un contracte a través d'altres convocatòries competitives (ICREA, MINECO o programes europeus), algunes de les quals també han disminuiit el nombre de persones a contractar.

Però les conseqüències de la situació que acabem de descriure no són només d'ordre quantitatiu sinó també qualitatiu: la major presència d'investigadors a temps complet en els instituts de recerca facilita, lògicament, que els inputs de recerca quantificables en els diversos sistemes d'avaluació puguin ser més elevats en els grups de recerca d'aquests darrers que en els de les universitats, i que per tant tinguin més possibilitats d'aconseguir projectes en convocatòries per via competitiva.

El panorama descrit pot comportar, doncs, que des de l'àmbit universitari es vegi els instituts de recerca com a competidors que han acabat passant al davant, captant personal i recursos econòmics, mentre que les universitats s'han de limitar fonamentalment a la docència i amb menys possibilitats reals d'investigar. Però el cert és que, actualment, les reduccions de pressupost i l'escassetat de personal a l'hora de consolidar els equips de recerca estan afectant totes les institucions de recerca.

Davant d'aquesta situació, i tenint en compte les retallades pressupostàries, que en el cas que ens ocupa s'han traduït en la reducció i fins i tot supressió de convocatòries destinades tant a contractar personal com a finançar la recerca, cal considerar la necessària col-laboració entre institucions. És clau buscar punts de contacte entre els objectius de recerca dels diferents centres, crear projectes interinstitucionals, amb més possibilitats d'obtenir recursos, com s'ha demostrat amb alguns casos recents d'associació d'instituts amb universitats, per exemple, en la convocatòria d'SGR 2014-2017. Més enllà de veure la dualitat universitatinstitut de recerca com dues opcions excloents, hem de veure les oportunitats de col-laboració, tant entre universitats $\mathrm{i}$ instituts com entre els diferents instituts, fins i tot quan es dediquen a branques de la ciència aparentment allunyades, que poden permetre projectes interdisciplinaris. Les possibilitats de collaboració són múltiples, i poden obrir noves portes i vies de recerca.

En definitiva, després de l'etapa de canvi iniciada l'any 2001, hem d'avançar encara cap a la creació d'un altre model de recerca. Per això és fonamental analitzar els objectius i temàtiques amb punts de coincidència, aprofitar els recursos humans i econòmics en els diversos centres i reorientar la manera de fer recerca, tot i que serà necessari un important esforç per adaptar-nos-hi. Sigui com sigui, algunes de les actuals convocatòries ja es plantegen valorant aquestes associacions entre institucions, buscant també la interdisciplinarietat, sense les quals a vegades difícilment es poden presentar propostes competitives.

Maria Carme Belarte
Professora ICREA
adscrita a l'Institut Català d'Arqueologia de Catalunya
Pl. d'en Rovellat, s/n, 43003 Tarragona
cbelarte@icac.cat
Professora ICREA 43003 Tarragona 
Centres d'investigació i recerca arqueològica a Catalunya: reflexions des de l'Agència Estatal CSIC

\author{
Xavier Terradas, Ignacio Clemente, \\ Juan F. Gibaja, Juan J. Ibáñez, \\ Millán Mozota, Ariadna Nieto, Sílvia \\ Valenzuela
}

D'acord amb els continguts de la seva plana web, l'Agència Estatal Consell Superior d'Investigacions Científiques (CSIC) és la major institució pública dedicada a la investigació a l'Estat espanyol i la tercera d'Europa. Adscrita a la Secretaria d'Estat de Recerca, Desenvolupament i Innovació del Ministeri d'Economia i Competitivitat, el seu objectiu fonamental és desenvolupar i promoure la investigació científica i tecnològica, de caràcter pluridisciplinari, en benefici del progrés científic i tecnològic. Per això té com a missió contribuir a l'avanç del coneixement i al desenvolupament econòmic, social i cultural, així com a la formació de personal i l'assessorament d'entitats públiques i privades en aquestes matèries.

El CSIC disposa en l'actualitat de més de 15.000 treballadors (1.654 d'ells a Catalunya), dels quals més de 3.000 són investigadors en plantilla i altres tants doctors i científics en formació. Aquesta xifra representa el 6\% del personal dedicat a la Recerca i Desenvolupament a Espanya, que genera aproximadament el $20 \%$ de la producció científica a l'Estat. En tractar-se d'una institució estatal, és constituït per una xarxa de centres i instituts, propis i mixtos (amb gestió compartida amb universitats, comunitats autònomes i altres organismes), distribuïts arreu de la geografia estatal a més de l'Escola Espanyola d'Història i Arqueologia de Roma. A Catalunya el CSIC disposa de 23 centres, propis i mixtos, on també participa a diferents fundacions, consorcis de recerca i parcs científics.

La recerca arqueològica realitzada a Catalunya des del CSIC té una llarga història tot i que s'ha dut a terme amb una certa discontinuïtat. Els orígens es remunten a l'any 1958, quan es va constituir l'Instituto de Arqueología del Mediterráneo sota la direcció dels Drs. Martín Almagro i Lluís Pericot, tasca prosseguida pel Dr. Joan Maluquer i que finalitzà als anys vuitanta quan la seva darrera titular, la Dra. $\mathrm{M}^{\mathrm{a}}$ Eugenia Aubet, va optar per una càtedra universitària. Després d'uns anys sense personal vinculat ni activitat científica en aquest àmbit, es va reprendre la recerca arqueològica de la mà de la Dra. Assumpció Vila a la Institució

5. <http://www.csic.es/presentacion>.
Milà i Fontanals de Barcelona, centre adscrit a l'àrea científica d'Humanitats i Ciències Socials del CSIC. ${ }^{6}$ Així, en aquest institut es va crear l'Àrea d'Arqueologia, que l'any 1994 es va reconvertir en Laboratori d'Arqueologia. Degut a les canviants regulacions administratives i científiques l'any 2004 es va constituir el Departament d'Arqueologia i Antropologia, en el marc del qual s'han anat succeint diversos grups de recerca fins que, recentment (2014), han quedat instituïts els dos grups de recerca arqueològica vigents: Complexitat i Dinàmiques Socio-Ecològiques (CASES) i Arqueologia de les Dinàmiques Socials (ADS). Els components d'aquest darrer grup som els autors d'aquesta contribució.

Durant el període considerat en aquest espai de debat el nostre grup de recerca ha mantingut una presència notable i creixent dins la política científica vinculada a la recerca arqueològica que s'ha desenvolupat a casa nostra. Així, per exemple, en l'àmbit institucional, hem participat a les diferents taules de treball desenvolupades en el marc del Pla Integral per l'Arqueologia a Catalunya (PIACAT), promogut per la Direcció General del Patrimoni Cultural i aprovat pel Departament de Cultura de la Generalitat de Catalunya l'any 2009, on es pretenia dissenyar i posar les bases del futur de l'arqueologia catalana. Aquestes accions van derivar en la creació de la Comissió de Recerca d'Arqueologia i Paleontologia de la Generalitat de Catalunya, on sempre hi hem tingut representació institucional, i en la redacció del Pla de recerca de l'Arqueologia i la Paleontologia catalanes, presentat per la Generalitat l'any 2014.

Com a grup de recerca hem obtingut el reconeixement de Grup de Recerca Consolidat per part de l'Agència de Gestió d'Ajuts Universitaris i de Recerca (AGAUR), constituint des de l'any 2005 un grup mixt, amb doble filiació, integrat per personal investigador adscrit a la Institució Milà i Fontanals del CSIC i al Departament de Prehistòria de la Universitat Autònoma de Barcelona (grups 2005SGR-00829, 2009SGR-00734 i 2014SGR-1169). Igualment, duem a terme projectes de recerca en col-laboració amb d'altres investigadors adscrits a diferents universitats catalanes. Aquests exemples constitueixen una bona mostra de la implicació institucional del nostre grup de recerca a les diferents iniciatives vinculades a la política científica general i estratègies de recerca concretes desenvolupades per aquelles institucions catalanes responsables del patrimoni cultural i la seva gestió i investigació a casa nostra.

Tanmateix, i també en el marc de convocatòries competitives avaluades per l'AGAUR, hem gaudit de diversos ajuts com ara els vinculats a la creació de xarxes temàtiques (XT), a la realització d'intervencions arqueològiques internacionals (EXCAVA), o bé els projectes quadriennals de recerca en matèria d'arqueologia i paleontologia per al període 2014-2017, a més d'instituir convenis de cooperació específica amb la Direcció General del Patrimoni Cultural de

6. Vila, A.; Clemente, I. \& Terradas, X. (2016). Una auténtica celebración: los 25 años de Arqueología en la Institució Milà i Fontanals - CSIC en Barcelona. Revista Atlántica-Mediterránea de Prehistoria y Arqueología Social, 18: 163-178. 
la Generalitat de Catalunya. En el mateix sentit, la nostra capacitat de captació de recursos no s'ha limitat a l'àmbit català, sinó que hem obtingut diversos projectes concedits per institucions europees (European Research Council) i, sobretot, estatals (Ministerio de Economía, Industria y Competitividad i Ministerio de Educación, Cultura y Deporte), a través de diverses convocatòries de la Subdirección General de Proyectos de Investigación, del Programa Estatal de Fomento de la Investigación Científica y Técnica de Excelencia, de la Fundación Española para la Ciencia y la Tecnología i del Instituto del Patrimonio Cultural de España. En els darrers anys hem endegat també convenis puntuals amb fundacions privades que han reportat fons econòmics per als nostres projectes de recerca. Independentment de la provinença dels fons, una gran part s'ha destinat a implementar i executar projectes de recerca dirigits vers la resolució de problemàtiques arqueològiques a través de casos d'estudi catalans. D'aquesta manera, queda clara la vinculació al territori de la nostra institució i grup de recerca, sense que això impliqui la renúncia a d'altres projectes de caràcter internacional i dirigits vers qüestions metodològiques o d'àmbit més general.

L'Agència Estatal Consell Superior d'Investigacions Científiques, com tantes altres institucions, encara no s'ha recuperat dels efectes de la crisi que va sacsejar l'economia espanyola a finals de l'any 2008. Si bé el CSIC es va beneficiar de la creixent bonança econòmica dels inicis del segle xxI que va repercutir en un increment considerable dels recursos dirigits vers la recerca (places d'investigador en plantilla, infraestructures i mitjans, convocatòries pròpies de beques i contractes...), contribuint d'aquesta manera a reduir les diferències històriques amb altres institucions homologables en l'àmbit europeu, aquesta tendència es va aturar bruscament amb la irrupció de la crisi, sense que encara hagi recuperat els actius dels quals disposava antany.

Amb relació al finançament, el pressupost basal de la nostra institució es destina a cobrir les despeses generades del funcionament normal del centre, sense que es destini cap quantitat a cobrir el cost d'infraestructures de recerca, desenvolupament de projectes o contractació de personal científic o tècnic. En aquest sentit, els recursos que haurien de permetre cobrir els àmbits esmentats els hem de generar nosaltres mateixos a partir de la sol-licitud d'ajuts i projectes en diverses convocatòries competitives (valguin els casos citats més amunt com a exemple), amb la incertesa i possibilitats variables d'èxit que això comporta. A més, sovint ens trobem amb la dificultat que cal cofinançar part d'aquests ajuts a partir de fons propis dels grups de recerca, dels quals no gaudim, fet que condiciona o sovint impossibilita la consecució d'aquests projectes i el desenvolupament dels objectius inicialment perseguits.

En el marc de les convocatòries del CSIC relatives a la nova contractació de personal vinculat a la recerca, les convocatòries de places de funcionari no han assolit encara l'oferta existent abans de la crisi, i les de personal tècnic destinat a centres d'humanitats són pràcticament inexistents. Així doncs, la capacitat de creixement de personal per part dels diferents grups de recerca del CSIC passa per la seva capacitat d'atreure i reclutar investigadors i investigadores que hagin guanyat concursos en l'àmbit internacional $\mathrm{O}$ estatal, sempre que disposin dels recursos per afrontar el cofinançament dels seus contractes. En aquest mateix sentit, algunes convocatòries de contractació temporal per part del CSIC emmarcades en el programa JAE van anar desapareixent progressivament amb els efectes de la crisi econòmica i no han tornat a ser convocades.

Finalment, amb relació a la formació de nou personal investigador, tot i el lideratge del CSIC en la producció científica de l'Estat, la seva idiosincràsia no li permet de desenvolupar programes propis de doctorat ni de màster, fet que restringeix la nostra capacitat d'atracció de personal investigador novell. La reducció de les convocatòries emmarcades dins del programa JAE que hem esmentat abans, ha comportat que l'única convocatòria pròpia del CSIC per a la contractació de personal en formació que segueixi vigent sigui la d'introducció a la recerca, únicament de dos mesos de duració, i adreçada a estudiants de programes de màster universitaris. Per altra banda, inexplicablement, els centres del CSIC es veuen sistemàticament discriminats de la convocatòria de contractació de personal investigador novell realitzada per la Generalitat de Catalunya (FI): els 23 centres del CSIC ubicats a Catalunya reben un total de 5 o 6 beques per any, quan les grans universitats del país (UB i UAB) en reben més de 40 cadascuna. Això provoca que, malgrat que el CSIC pugui oferir un marc idoni per a la formació de nou personal investigador, la capacitat real d'optar a personal becari en el marc de convocatòries públiques catalanes sigui molt limitada.

Tot plegat fa que, malgrat que el Consell Superior d'Investigacions Científiques pugui oferir unes condicions que a priori es podrien considerar idònies per a desenvolupar diferents activitats vinculades a la recerca arqueològica a Catalunya, la situació real sigui molt distant de l'esperada. Per una banda, diversos problemes estructurals del CSIC i de l'administració estatal dificulten que la recerca pugui assolir un finançament suficient per a acomplir els objectius científics plantejats. Les comparacions pressupostàries amb agències estatals d'investigació d'altres països europeus mostren clarament com la nostra institució no obté un finançament d'acord amb la posició que l'Estat espanyol vol assolir dins la construcció política i econòmica europea. A més, el fet que el nostre centre s'ubiqui en un espai allunyat de la centralitat espanyola i que la recerca arqueològica es desenvolupi en el si de les humanitats i ciències socials són raons que allunyen encara més la nostra praxi científica de les millors opcions de finançament econòmic. Aquest fet es tradueix en greus dificultats per a desenvolupar els programes de recerca i en seriosos impediments a l'hora de contractar personal científic, tècnic i en formació, repercutint en una reducció progressiva del nombre de personal investigador i el seu creixent envelliment.

Per altra banda, malgrat les mostres evidents que certifiquen la presència notable i creixent del CSIC dins la política científica vinculada a la recerca cata- 
lana, la indubtable capacitat de captació de recursos econòmics i humans, així com el fet que tots aquests actius repercuteixin en estratègies i accions científiques desenvolupades a Catalunya, el CSIC és sovint percebut com un agent estrany o aliè a la realitat catalana. Com hem esmentat abans, aquest fet és evident en la resolució d'algunes convocatòries d'ajuts gestionades per l'AGAUR.

Malgrat els problemes esmentats en aquesta contribució, el nostre compromís amb l'enfortiment de l'estructura científica del sistema català i amb el desenvolupament de la recerca arqueològica a Catalunya és ferm i irrenunciable. Esperem que aquestes reflexions puguin contribuir a enriquir el debat generat des d'aquesta iniciativa i repercuteixin en accions que contribueixin decisivament a una millora generalitzada de les condicions sota les quals es duu a terme la recerca arqueològica a Catalunya.
Xavier Terradas Ignacio Clemente Juan F. Gibaja

Juan J. Ibáñez Millán Mozota Ariadna Nieto Sílvia Valenzuela

Consell Superior d'Investigacions Científiques (CSIC) Institució Milà i Fontanals Arqueologia de les Dinàmiques Socials Egipcíaques, 15. 08001 Barcelona 